NBER WORKING PAPER SERIES

\title{
THE EFFECTS OF HMO AND ITS FOR-PROFIT EXPANSION ON THE SURVIVAL OF SPECIALIZED HOSPITAL SERVICES
}

\author{
Yu-Chu Shen \\ Working Paper 12374 \\ http://www.nber.org/papers/w12374 \\ NATIONAL BUREAU OF ECONOMIC RESEARCH \\ 1050 Massachusetts Avenue \\ Cambridge, MA 02138 \\ July 2006
}

I would like to thank the Naval Postgraduate School Research Initiation Program for funding this research, Shou-Tzu Lin for excellent programming assistance, and Laurence Baker and Glenn Melnick for their comments and data. All errors are my own. The views expressed herein are those of the author(s) and do not necessarily reflect the views of the National Bureau of Economic Research and Naval Postgraduate School.

(C2006 by Yu-Chu Shen. All rights reserved. Short sections of text, not to exceed two paragraphs, may be quoted without explicit permission provided that full credit, including (C) notice, is given to the source. 
The Effects of HMO and Its For-Profit Expansion on the Survival of Specialized Hospital Services

Yu-Chu Shen

NBER Working Paper No. 12374

July 2006

JEL No. I11, L30

\begin{abstract}
$\underline{\text { ABSTRACT }}$
This study examines the effect of HMO and for-profit HMO share on the survival of safety net services and profitable services in hospitals. Using data from 1990-2003 and proportional hazard models, I find that hospitals in high HMO markets started out having lower hazard of shutting down services in 1990-1994 than those in low HMO markets, but their hazard rates increase over time. By 2000-2003, hospitals in high HMO markets ended up with higher risk of shutting down profitable services than those in low HMO markets. Conditional on overall HMO penetration, markets with higher for-profit share of HMOs have higher hazard of shutting down services, and the gap in survival between high and low for-profit HMO markets is bigger in high HMO areas. Lastly, I find that the hazard rate of shutting down profitable services is comparable among not-for-profit, for-profit, and government hospitals, while the hazard of shutting down safety net services is the highest in for-profit hospitals and lowest in government hospitals.
\end{abstract}

Yu-Chu Shen

Graduate School of Business and Public Policy

Naval Postgraduate School

555 Dyer Road

Monterey, CA 93943

and NBER

yshen@nps.edu 


\section{Introduction}

Over the past decade, the US health care system has undergone significant structural changes, including changes in hospital ownership, increasing competition in the HMO industry, and increasing for-profit presence in many health care sectors. Perhaps the most profound market change is the emergence of Health Maintenance Organizations (HMO). Under the traditional fee-for-service payment system, hospitals can charge services based on cost and have little incentive to engage in cost saving practices. HMOs had adopted strategies that allowed them to aggressively control health care costs, including negotiating deep discounts with providers and restricting access to providers outside of the network (Bamezai et al 1999; Draper et al 2002). Hospitals responded to the explosion of HMO growth by reducing cost of operation (Gaskin and Hadley 1997; Bamezai et al 1999; Morrisey 2001; Shen and Melnick 2004). However, there is little empirical evidence on whether they achieve this cost saving at the expense of patient welfare. For example, do hospitals become hesitant to adopt life-saving technology because its expected profit is too low in the HMO environment? Do hospitals drop safety net services under the financial pressure from HMO?

While several studies have found that higher HMO presence led to a slow down of technology diffusion in hospitals (Cutler and McClellan 1996; Cutler and Sheiner 1997; Baker 2001; Baker and Phibbs 2002), there has not been studies investigating whether higher HMO presence increase the risk of hospitals shutting down safety net services (such as substance abuse treatment center, emergency department). Furthermore, despite retrenchment in the overall HMO penetration rate since 2000 (Figure 1), there is a growing for-profit presence in the HMO

market (Figure 2). Classic microeconomics framework would suggest that the profit maximizing for-profit HMO plans would exert even greater financial pressure on its providers than not-for- 
profit HMO plans. Whether such pressure translates to hospitals dropping unprofitable services remains to be examined. This study aims to fill these gaps in the literature. In particular, I address the following research questions: (1) Does higher HMO penetration increase the risk of shutting down specialized services in hospitals? (2) Conditional on overall HMO penetration, does the risk of service shut down vary by whether hospitals are operating in predominantly forprofit HMO markets or predominantly not-for-profit HMO markets?

I contrast the analysis between safety net services (Gaskin 1999; Zuckerman et al 2001) and other public health services that are relatively more profitable (Horwitz 2005). Examples of safety net services include emergency department, HIV/AIDS services, substance abuse services; examples of public health and profitable services include maternity care, birthing room, and sports medicine. The two types of services allow me to contrast any possible differential exit pattern due to their expected profitability. Using hospital and HMO data from 1990 to 2003, I first compare service exit rates in hospitals operating in Metropolitan Statistical Areas (MSAs) with varying degrees of HMO penetration. I then compare the risk of hospital service exit in MSAs where for-profits have gained a large share of the HMO market to MSAs where not-forprofit plans retain a substantial share of HMO enrollment.

Shutting down specialized services in one hospital can have rippling effects in the community. When a hospital shuts down a specialized service, many patients will suffer disruption of care as they scramble to identify the next available hospital. This is especially unsettling for patients requiring multiple treatment visits such as pregnancy or substance abuse problems. When safety net services are shut down, the largest impact would be felt by lowincome population in the area, as they are the major users of these services. It also takes a toll on neighbor hospitals as they would have to absorb the influx of patients. Exploring how HMO 
presence affects these exit decisions allow us to understand some of the pathways in which HMO affects patient welfare.

The rest of the paper proceeds as follows. I discuss the background literature in section 2. I describe the data sources and empirical strategy in section 3. I present the results in section 4 , and conclude in section 5.

\section{Background}

Majority of literature examining the effect of HMO on hospital behavior focused on the financial side of the operation (see Morrisey 2001 for a review). In general, the literature found that hospitals in high HMO penetration markets tend to have slower revenue and cost growth than those in low HMO penetration markets. A recent study further found that hospitals in predominantly for-profit HMO markets have experienced slower cost growth than those in predominantly not-for-profit HMO markets (Shen and Melnick 2004). However, there is little evidence on whether the cost saving was achieved by shifting away from unprofitable services or by offering services that can attract healthier and wealthier patients.

The conceptual effect of HMO on service offering is ambiguous (Morrisey 2001; Baker and Phibbs 2002). Consider the following two competing hypotheses. If cost can be reduced through economies of scale, then the financial pressure from HMO would drive hospitals to specialize in particular, perhaps more profitable, services. Given the scarce resources,

specializing in new profitable services might come at the expense of shutting down existing less profitable services. On the other hand, economy of scope might be the hospital's dominant strategy. If a hospital wants to attract health plans by position itself as the one-stop care center, it would add services that are complementary to those it already provides and rely on economy of 
scope to maintain its financial position. In this case, we would not see much difference in service exit rates across HMO markets. A commonly held belief is that firms in high HMO markets will tend to adopt new services later than firms in low HMO markets, either because the downward pressure from HMO lowers the expected profitability of the new service, or because the deterioration of overall financial positions of hospitals can no longer support investment in new services (Baker and Phibbs 2002).

There is less discussion about whether and how the increasing for-profit presence in HMO markets would affect those service shut down decisions. However, microeconomics framework usually models for-profit entities as profit maximizers while places more emphasize on non-monetary objectives in not-for-profit entities. If the HMO market is predominantly forprofit, one would expect the downward pressure on hospital revenue stream to be greater, and thus even slower adoption of technology that require substantial financial investment and faster exit rate of unprofitable services.

The discussion of HMO's potential effect on those service adoption and shut down decisions should not overlook the changing landscape of HMO activities since the late 1990s. The HMO industry enjoyed a period of rapid growth in the early 1990s, the explosion of growth was fueled by concerns of rising health care cost during that period. However, such aggressive strategies created a deep mistrust in consumers in the later part of the 1990s (Swartz 1999, Robinson 2001). The negative portrayals of managed care plans in the media further created a chasm between managed care and consumers/providers, even when a consumer might not have felt dissatisfied with his or her own health plan (Blendon et al. 1998). Shen and Melnick (2006) found that HMO and managed care plans in general have lost their cost containment ability of the provider market in the $21^{\text {st }}$ century. Some of that were due to HMOs relaxing their many 
once restrictive network requirements and deep discounting (Draper et al 2002; Mays et al 2003, 2004; Marquis et al 2005). In this paper, I take into account potential differential effects of HMO on hospital service exit rates during different phases of HMO growth.

The empirical literature studying the effect of HMO on service offering decisions (mainly studies of adoption decisions) is mixed. Some found higher HMO market shares to be associated with decreased availability of technology in areas such as angioplasty (Cutler and McClellan 1996), magnetic resonance imaging (Baker and Wheeler 1998; Baker 2001), and mid-level neonatal intensive care units (Baker and Phibbs 2002). Similarly, using state level managed care data, Cutler and Sheiner (1997) examined a wide set of technology and services that all involved a steep sunk cost, and found that managed care has reduced the diffusion of medical technologies. On the other hand, Baker and Phibbs (2002) found that higher HMO market share has not slowed down the rate of adoption of most advanced high-level NICU units. Morrisey (2001) discussed a working paper in which the authors found that increasing HMO penetration is associated with increasing admission in pediatric services among general acute hospitals. Baker and Spetz (1998), examining an index of hospital technological advancement and found no HMO effect. The literature to date all focused on the adoption decision of technology with a high fixed cost. My study instead will focus on the other end of the spectrum-I study exit rate of services that do not necessarily require a substantial sunk cost.

The discussion about the survival of hospital services also cannot ignore an important aspect of hospital industry: it is predominantly run by not-for-profit organizations. While there is a wealth of empirical literature exploring the role of ownership in different aspects of hospital operation (see reviews in Sloan 2000; Shen et al 2005; Eggleston et al 2006), there have been few empirical studies that investigated the ownership effect on service offerings in hospitals. One 
hypothesis is that for-profit hospitals might respond to change in demand quicker than others because they have easier and quicker access to the capital market (Hirth 1999). Earlier studies, examining technology adoption before the rise of HMO and prospective payment system, found that there were no statistically significant differences in adoption between not-for-profit and forprofit hospitals (Sloan 2000). A recent study, using a panel of US hospitals from 1988 to 2000, examined 35 services in hospitals that can be categorize into different profitability categories. The author found that for-profits are most likely to offer relatively profitable medical services; government hospitals are most likely to offer relatively unprofitable services; and nonprofits often fall in the middle (Horwitz 2005). The present analysis of service shut down risks will take into account hospital ownership differences.

In summary, although there is a wealth of literature examining how HMOs affect the financial side of hospital operation, there is less focus on understanding its effect on service adoption and disruption. Changing the mixture of service offered is certainly one way to improve the financial position of the hospital. Few studies examine service adoption decisions and none on exit behaviors. This study aims to fill the gap.

\section{Empirical Methods}

\section{Overview of Empirical Strategy}

The primary data sources for the analysis are the American Hospital Association (AHA) annual surveys, Hospital cost report from the Center for Medicaid and Medicare Services (CMS), and the HMO enrollment and ownership data provided by Laurence Baker and Interstudy. The unit of analysis is hospital and I examine the risk of service shut down between 
1990 and 2003. I use proportional hazard models to analyze the effects of HMO and for-profit share of HMO on the hazard of hospitals shutting down safety net and profitable services.

\section{Sample and Data Sources}

The analytical sample includes all general, acute, short-stay hospitals in metropolitan statistical areas (MSA) between 1990 and 2003. Separate indicators of the different ownership structure (not-for-profit, for-profit, government, whether ownership was changed) are included in the analyses. My analysis utilizes all 14 years of information with two exceptions. Analysis of child wellness and AIDS services are limited to 1994-2003 period because data are not available before $1994 .^{1}$ I limit the sample to hospitals in MSAs because the majority of HMO enrollment occurred in MSAs during this period, and hospitals in rural areas behave differently from those in urban areas. Lastly I exclude a handful of Kaiser Foundation hospitals since they serve exclusively Kaiser health plan enrollees. This sampling frame contains about 3000 hospitals in 322 MSA markets in each year for a total of 33000 hospital-year observations.

Hospital Data. Hospital data primarily come from the American Hospital Association (AHA) Annual Surveys and Medicare hospital cost reports by CMS. Together, they provide detailed information on hospitals' financial performance, inpatient and outpatient utilization, and other characteristics. I supplement hospital ownership data with those provided by Frank Sloan. ${ }^{2}$ Particularly important to this project are the service measures hospitals self reported to the AHA surveys. I describe the services and limitations in AHA data in more details below.

HMO Data. HMO is one of many types of managed care plans. Managed care plans are

\footnotetext{
${ }^{1}$ The presence of child wellness service was not recorded until 1994. The survey questions for AIDS were changed in 1994 in such a way that I cannot construct a consistent time series.

${ }^{2}$ The underlying data are still from AHA, Dr. Sloan tracked down CEO and CFO of hospitals with suspicious ownership change.
} 
antithesis of fee-for-service plans and are loosely defined as health plans that engage in activities that reduce high levels of utilization such as utilization review board and deep discounts with providers. There are two practical reasons to focus on HMO. First, it accounts for majority of managed care activities, especially during the 1990s. Second, this is the only form of managed care plan whose enrollments were tracked consistently over the years and whose data are available for sufficient number of years to carry out exit analysis. As discussed in sensitivity analysis later, I also experiment with using a more comprehensive managed care measure that includes both HMO and PPO (preferred provider organizations). I use the HMO only measure in my main analysis because it is more reliable.

Overall HMO penetration rates at the MSA level between 1990 and 2003 are provided by Laurence Baker of Stanford University. The HMO penetration rate is measured as total HMO enrollment as a share of MSA population. The underlying data sources are from HMO Census conducted by the Group Health Association of America from 1990 and 1994 and by InterStudy from 1995 to 2003. Detailed methodology of the smoothing between the two data sources can be found in Baker (1997).

In addition, HMO ownership information between 1994 and 2003 was obtained from Interstudy. ${ }^{3}$ The ownership data include detailed information about enrollment levels, ownership of each plan, and MSAs served by the plan. I use this data source to construct percent HMO enrollment that are for-profit in each MSA between 1994 and 2003.

Other Data. I further supplement the hospital and HMO data with other information to capture relevant market characteristics. These include the area wage index from the PPS Impact File, population characteristics from the Area Resource File, and a variable-radius based hospital

\footnotetext{
${ }^{3} 1999$ and 2002 ownership information were not available. I use the adjacent two years to interpolate the for-profit HMO enrollment share for those two years.
} 
competition measure (Herfindahl index) provided by Glenn Melnick.

\section{Variable Construction}

Hospital Service Variables. I focus on services that are commonly viewed as safety net services as well as services that are relatively profitable. Using Zuckerman et al (2001) as the blueprint, safety net services include emergency department, trauma center, HIV/AIDS services, inpatient substance abuse services, and outpatient substance abuse services. ${ }^{4}$ Profitable services include maternity care, birthing room, child wellness service, women health center, and sports medicine (Horwitz 2005). It should be noted that while maternity care is an important safety net service, it is considered a revenue generating service especially since a growing share of births were being covered by Medicaid (Zuckerman et al 2001). Therefore I categorize maternity care under profitable service.

Because service variables are obtained from AHA surveys, which are self-reported, one would be concerned with data reliability. However, there is no reason to believe that reporting errors would be correlated with HMO penetration. Another limitation of AHA data is that there are missing values over the years, especially toward the later years. When hospitals did not report whether they offered a service in a given year, I impute the values using information from adjacent years (for example, if a hospital is missing 1992 value but report having a given service in 1991 and 1993, I would impute 1992 as having such a service). If there are more than two consecutive missing values, no imputation is done and observations are excluded from the analysis. Depending on the service, I impute $3.5-4.7 \%$ of the data.

\footnotetext{
${ }^{4}$ Zuckerman et al (2001) analyze several additional safety net services such as burn unit and neonatal intensive care unit. I do not include burn unit because there are too few hospitals offering this service that I do not have enough sample size to analyze exit behavior. I do not include neonatal intensive care unit, because such unit requires a high sunk cost that hospitals rarely shut it down (Baker and Phibbs 2000). For the same reason I do not estimate the risk of shut down for cardiac and diagnostic imaging technology.
} 
Defining Service Adoption and Exit Years. In order to analyze the risk of service shut down, I also need to track when a hospital started offering that service. With the cleaned AHA data, I construct adoption and exit variables for each of the services. I use the adoption definition in Baker and Phibbs (2002) — I define adoption year as the first year of the first consecutive pair of years in which the hospital says it offers a given service. Using this definition is more conservative than defining adoption year as the first year that a hospital says it offers a given service, but it minimizes sporadic reporting errors. Since the data series started in 1990, if a hospital reports having a given service in both 1990 and 1991, then the adoption year would be 1990. Consequently, all hospitals that have offered a given service before 1990 would have an adoption year of 1990. Exit years are defined using the following logic: (1) there must be an adoption year between 1990 and 2002; (2) exit year is the year after the last year in which the hospital offers a given service. Because I use the more conservative adoption definition, the earliest exit occurs in 1992.

HMO Penetration Variables. I define overall HMO penetration as total HMO enrollment divided by the total population in an individual MSA. MSA is the common market definition used in antitrust analysis of health insurance geographic markets (Hymen and Kovacic, 2004). I categorize hospitals according to whether they operated in MSAs with low $(<15 \%$ of population is enrolled in HMO), medium $(15-25 \%)$, and high levels of HMO penetration $(>25 \%)$. The categorical variables allow for a more intuitive interpretation of the hazard ratio of service shut down. The categorical variables can also capture potential nonlinearity in the effects of HMO penetration rates.

For this analysis, I categorize HMO markets based on the average HMO penetration of a given MSA over the entire analysis period. I take this approach instead of using the actual HMO 
penetration rates in each year for the following reasons. One concern is that HMO plans might selectively choose to enter a particular provider market that would give them the best market advantages, and therefore the relationship between HMO growth and hospital service offer decisions are endogenously related. I use the average HMO penetration rate as an exogenous proxy for the actual and expected HMO market shares during this period. The idea is that areas that had high average HMO penetration in earlier years also tended to have high growth in markets in later years (Baker and Phibbs, 2002). In an alternative specification, I use the peak year's HMO penetration (1999) instead of the average HMO penetration rates (Shen and Melnick 2004). It turned out that those two measures are highly correlated (correlation above 0.90) and results are similar. Using this approach also avoids the rare situation in which the same hospital might appear in medium HMO market in one year but high HMO market in another. One can think of the HMO categories I use based on average or peak year penetration rate as instruments for the actual growth rates in the HMO industry. Using this definition and the cutoff described above, $23 \%$ of the hospital sample is in low HMO markets, $39 \%$ of the hospital sample is in medium HMO market, and the remaining $38 \%$ of the hospital sample is in high HMO markets.

For my second research question, I add additional information about which ownership dominates a particular HMO market. I define percent for-profit as the number of enrollees in for-profit HMO plans divided by total HMO enrollment in an MSA. Like the HMO penetration measure, I also use the average for-profit share of HMO between 1994 and 2003 to construct the three levels of for-profit HMO categories. Using the average for-profit HMO share has an additional benefit for this analysis: it allows me to utilize all years of service data instead of just 1994 to 2003. The assumption is that MSAs with high for-profit HMO presence in later part of 
1990s also have high for-profit presence in the early 1990s. I believe this is a reasonable assumption because such high correlation does exist in the overall HMO penetration measure. The cutoff points for low, medium, and high for-profit HMO markets are $0-50 \%, 50-90 \%$, and $>90 \%$, respectively. About $36 \%, 21 \%$, and $43 \%$ of hospitals are in low, medium, and high forprofit HMO markets, respectively.

Other Hospital and Market Variables. I include the following hospital measures in the model: hospital ownership (for-profit and government vs. not-for-profit), teaching hospital, hospital system membership, casemix of the patient population, size of the hospital (both inpatient discharges and outpatient visits), and competitiveness (measured by Herfindahl index). The hospital Herfindahl index is constructed using a variable-radius approach based on patient flow (Bamezai et al 1999). I include the following area characteristics: share of hospitals within 15-mile radius that is for-profit, share of hospitals within 15-mile radius that is owned by government, cost of living (as proxy by wage index) of the hospital's MSA, per capita income and population size of MSAs.

\section{Estimating Proportional Hazard Models}

I analyze the hazard of shutting down each service separately using proportional hazard models. My analytical plan consists of two parts. I first establish the effect of overall HMO penetration on the risk of hospital service shut down. I then examine the effect of for-profit HMO level on service shut down risks separately for low, medium, and high HMO markets. As Figure 2 shows, the distribution of for-profit share of HMOs vary considerably across the three categories of HMO markets. The separate analysis in the second part would allow me to capture 
potential differential provider behaviors when downward financial pressures from HMO are different. The unit of observation is the hospital.

The Cox (1972) proportional hazard framework is the natural choice to examine rate of exit (Cox 1972; Shen 2002). It is nonparametric therefore I do not have to assume a priori whether service survival rate has a positive or negative dependence on time. Contrary to the study of technology adoption where all hospitals are at risk of adopting a technology before the first year of study period, only those who have adopted a service in prior years are at risk of dropping that service. Specifically, all hospitals that already offered the service by 1990 will enter the model in 1990. If a hospital did not adopt a service until 1994, then it does not enter the hazard model until 1994. If a hospital never offered a service, then it is not included in the model.

Another difference from studies of technology adoption is the type of proportional hazard model used in this analysis. Previous studies have used discrete time proportional hazard models (Cutler and McClellan 1996; Baker and Phibbs 2002). I use the Cox proportional hazard models instead of the discrete time proportional hazard models (proposed by Prentice and Gloeckler 1978) for the exit analysis for several reasons. First, the Cox proportional hazard model allows for more flexible specifications of the baseline hazard (both nonparametric or parametric). Second, discrete-time proportional hazard models can be very sensitive to starting values, and a small change in model specifications often resulted in no convergence of the maximum likelihood function. In the results section, I will show that for the main model, the results are virtually identical between the two approaches. Therefore I use the Cox models so we can compare key coefficients across all sensitivity analyses. I discuss other sensitivity specifications in the results section. 
In the proportional hazard framework, I define 12 intervals during which I can observe service exit. Suppose a hospital adopted a given service in year $t_{0}$, then intervals $\left(t_{0}, t_{2}\right],\left(t_{2}, t_{3}\right]$, $\left(t_{3}, t_{4}\right]$, and so on capture hospitals that offered a given service in the beginning year of that interval but dropped the service by the end year of the interval. Hospitals that adopted the service during the study period but did not drop such a service at the end of 2003 are censored at 2003. Note that for hospitals that adopted a given service after 1990, there will be fewer than 12 intervals. The probability that hospital $i$ drops service $j$ given that service $j$ was offered up until time $t$ is described by the following hazard function, $\lambda_{i j}(t)$ :

$$
\begin{aligned}
& \operatorname{Prob}\left(i^{\text {th }} \text { hospital exits service } j \text { in year } t \text { loffered service } j \text { until } t\right) \\
& =\exp \left(-\left(\beta_{1 \mathrm{j}} H M O_{i}+\beta_{2 \mathrm{j}} O W N E R_{i t}+\beta_{3 \mathrm{j}} X_{i t}\right)\right) \lambda_{0 j}(t)
\end{aligned}
$$

where $\lambda_{0 j}(t)$ is the baseline hazard rate for service $j$, which differs by the four Census regions; $H M O_{i}=$ indicators for whether hospital $i$ is in MSAs with low, medium, or high levels of HMO penetration rates, where the categorical $\mathrm{HMO}$ variable is based on the average HMO penetration between 1990-2003;

$O W N E R_{i t}=$ hospital ownership category (not-for-profit, for-profit, government) and whether ownership was ever converted between 1990-2003; $X_{i t}=\mathrm{A}$ vector of other hospital and market characteristics; The associated survival function at time $t$ is given by:

$$
S_{i j}(t)=\exp \left(-\int_{t_{0}}^{t} \lambda_{i j}(u) d u\right)
$$

The coefficient of interest is $\beta_{l j}$, as it captures the effect of HMO penetration on the hazard of exit for the $j^{\text {th }}$ service. A positive and statistically significant $\beta_{l j}$ would indicate that higher HMO penetration is associated with higher hazard of service exit. The coefficients can be estimated by applying maximum likelihood method to the Cox partial likelihood function for the above hazard 
function. I allow the baseline hazard rate to vary by the four Census regions. I also adjust the standard error to account for clustering at the MSA level. In presenting the results, I use hazard ratio instead of the actual coefficient for ease of interpretation: a statistically significant hazard ratio above one indicates higher risk of service exit in high HMO market, for example, compared to the low HMO market (the reference group). Conversely, a hazard ratio below one indicates a lower risk of exit compared to the reference group.

One key assumption of the proportional hazard model is that the hazard ratio is constant over time. In other words, the hazard ratio of service exit between high and low HMO markets is a fixed proportion and does not vary by time. In order to capture possible differential effects over time, I add interaction terms between the HMO variable and period indicators for 19951999 and 2000-2003, with 1990-1994 being the base period. The three periods roughly correspond to the booming, the maturing, and the backlash periods of HMO market (Shen and Melnick 2006).

To analyze the second question, whether a predominantly for-profit HMO market would exacerbate or mitigate service shut down, I modify eq (1) as follows:

$\operatorname{Prob}\left(i^{\text {th }}\right.$ hospital exits service $j$ in year $t$ loffered service $j$ until $\left.t\right)$

$$
=\exp \left(-\left(\beta_{1 \mathrm{j}} H M O_{i}^{F P}+\beta_{2 \mathrm{j}} O W N E R_{i t}+\beta_{3 \mathrm{j}} X_{i t}\right)\right) \lambda_{0 j}(t)
$$

Where

$H M O_{i}^{F P}=$ Indicators for whether hospital $i$ is in MSAs with low, medium, or high share of for-profit HMO plans.

Note that the variable $H M O_{i}$ drops out because I analyze for-profit HMO effect separately for low, medium, and high HMO markets. The key coefficient of interest, $\beta_{l}$, captures the effect of for-profit HMO penetration on the hazard of service shut down. I also add interaction terms between $\mathrm{HMO}^{\mathrm{FP}}$ variable and period indicators. I discuss other sensitivity analyses 
specifications in the results section.

\section{Results}

\section{Descriptive Statistics of HMO Activities and Hospital Characteristics}

Figure 1 shows the trend of overall HMO penetration from 1990 and 2003. It started out with just under 18 percent of the MSA population enrolled in HMOs in 1990. The enrollment reached peak in 1999 with over 28 percent of the population enrolled in HMO. There is a slight retrenchment of HMO enrollment in the 2000 s, with the average penetration in 2003 down to 25 percent of the population. The population-weighted average HMO penetration over this period is 23.5 percent. Some MSAs have an average of nearly zero penetration rate (such as Casper Wyoming, Albany Georgia), while others have an average penetration rate of over 50 percent (such as San Francisco, Oakland California, and Rochester New York). The average HMO penetration rates for low, medium, and high HMO markets are 8 percent, 19 percent, and 34 percent, respectively.

The level and growth of for-profit HMO vary by the three types of HMO markets (Figure 2). For-profit expansion is fastest in low HMO markets: for-profit share of the market grew from just under 60 percent to over 80 percent between 1994 and 2003. On the contrary, in the high HMO markets, the for-profit share of the HMO market remained constant around 50 percent of the market share through out the period. The average for-profit market share across time between 1994 and 2003 are 76 percent, 70 percent, and 50 percent for low, medium, and high HMO areas, respectively.

I summarize hospital and market characteristics by the three levels of HMO penetration in Table 1. As the number of observation shows, each HMO market category contains 
approximately $1 / 3$ of the hospital sample. Hospitals in low HMO markets are less likely to be not-for-profit (54 percent) than those in high HMO markets (71 percent). Hospitals in low HMO markets tend to be smaller than those in medium and high HMO markets-they have fewer total inpatient discharges and fewer outpatient visits. Casemix index of patient population is comparable across the HMO markets. In addition, low HMO market is associated with less competitive hospital markets. A Herfindahl index of 1 indicates a monopoly market while a nearly zero Herfindahl index indicates a competitive market. The average Herfindahl indices are 0.34 and 0.26 for low and high HMO markets, respectively. In terms of market characteristics, hospitals in high HMO markets are located in more populated MSAs and have slightly higher living costs (wage index is 0.94 and 1.14 for low and high HMO markets, respectively).

\section{Unadjusted Cumulative Survival Probability of Hospital Services}

Figure 3 shows the cumulative probability of survival for each of the 10 hospital services. In the present context, the survival curve represents the cumulative probability of continuing to offer a given service at the end of the time interval. The survival rate is 100 percent in the beginning of the time interval $\left(t_{0}\right)$ since that is the year of adoption, and the earliest exit only occurs in $t_{2}$ based on my exit definition described in section 2 . There are 12 time intervals except for HIV service and child wellness center which only have 9 intervals. A higher survival curve means fewer hospitals drop the service. An overview of Figures 3A (safety net services) and 3B (profitable services) reveals wide variation in survival rate. In general, safety net services have lower survival rate than profitable services, except for emergency department. The probability of survival is relatively high for emergency department—at the end of the 12-year interval, the cumulative survival probability is above 0.75 . On the other hand, the cumulative 
survival rate of inpatient substance abuse service is only about 0.25 at the end. Among profitable services, fewer hospitals drop birth related services compared to child wellness center and sports medicine. The cumulative survival rate for both maternity care and birthing room are above 0.7 by the end of the 12-year period.

Figure 3 also separates out the survival probability of each service by low, medium, and high HMO markets. Among safety net services, there does not appear to be different survival rates between high and low HMO markets except for emergency department: hospitals in high HMO markets (dotted line) have lower survival rate than those in low and medium HMO markets. Outpatient substance abuse service is an interesting case where hospitals in medium HMO markets consistently have high survival rate than both low and high HMO markets. Among profitable services, the cumulative survival rates are consistently lower for hospitals in high HMO markets except for sports medicine, where there appears to be no difference across the HMO markets. For maternity care and birthing room, the divergence in survival rate between low and high HMO markets does not appear until midway through the time series. The period interaction terms in the proportional hazard model would allow me to capture such period effect.

\section{Effect of HMO on the Hazard of Service Exit}

Figure 3 shows two general trends: the overall survival rates are generally higher for profitable services than safety net services; but survival rate differences between low and high HMO markets are more pronounced in profitable services. In this section I present the results from the proportional hazard models controlling for hospital and market characteristics.

Table 2 presents the effect of overall HMO levels on hazard ratio of service exit. The top panel shows the results for overall HMO effect over the entire period, with no period 
interactions. Each column represents a separate regression for each service. I provide the complete regression results of all included variables for each service in the appendix. I use hazard ratio to show how levels of HMO penetration are affecting the hazard of shutting down a given service. Take the comparison between hospitals in high and low HMO markets, for example. The hazard ratio is the ratio of the hazard rate between high and HMO markets, where the hazard rate is the probability that if service $j$ has not been dropped in year $t$, it will be dropped in year $t+1$. The reference group (low HMO markets) has a hazard ratio of 1 by default. A higher hazard ratio indicates that hospitals in high HMO markets have a higher risk of dropping the service relative to the reference group.

Top panel of Table 2 shows that with the assumption of a constant hazard ratio over time, I only observe two services where the risk of shutting down is higher in high HMO markets compared to low HMO markets. In particular, the hazard of hospitals in high HMO markets shutting down trauma center (child wellness center) is 1.48 (1.74) times higher than the hazard of hospitals in low HMO markets dropping such a service. On the other hand, I observe lower hazard of service exit for birth related services in medium and high HMO markets as compared to low HMO markets. For both birthing room and maternity care services, the hazard ratios associated with medium and high HMOs are all below 1, and statistically significant at the 0.10 level for medium HMO markets.

I also want to highlight the hazard ratio results of a few hospital characteristics (appendix). For-profit hospitals consistently have higher hazard rate of shutting down safety net services than not-for-profit hospitals (all hazard ratios are above 1). The hazard ratio of for-profit ownership ranges from 1.05 (emergency department) to 1.47 (HIV/AIDS services) and are statistically significant except for emergency services. On the other hand, the hazard of service exit is 
comparable between for-profit and not-for-profit hospitals for profitable services (the hazard ratio ranges from 0.97 to 1.05 ). The only exception is child wellness center, where for-profit hospitals have 1.83 times higher hazard of shutting down this service as compared to not-forprofit hospitals. Government ownership is generally associated with lower hazard of shutting down unprofitable services. In particular, the hazard ratio of shutting down emergency department is 0.62 when comparing government to not-for-profit hospitals. The hazard rates of shutting down profitable services are comparable between government and not-for-profit hospitals. Teaching hospitals have lower hazard rate of shutting down services, regardless of whether the service belongs to safety net or profitable category. The only exception is inpatient substance abuse where teaching hospitals are 1.27 times more likely than non-teaching hospitals to shut down this service. Larger hospitals are also less likely to shut down any services- the hazard ratio of size variables (outpatient and inpatient visits) are below one for all services. Lastly, higher hospital Herfindahl index (i.e., less competitive market) is associated with lower hazard rate of shutting down any of the services I examined. This likely reflects the fact that many of the hospitals in those monopolistic markets are the only hospital provider in that market.

The top panel of Table 2 indicates little difference in hazard rates of shutting down services between hospitals in low and high HMO markets. In the bottom panel, I estimate the same equation but allowing for differential HMO effects by periods (1990-1994, 1995-1999, 20002003). In 1990-1994, the hazard ratios of medium and high HMO markets across services are all below one relative to the low HMO markets, indicating that hospitals in low HMO markets have the highest exit rates during this period. In 1995-1999, hospitals in medium HMO markets still have much lower risk of shutting down services regardless of their profitability than hospitals in low HMO markets. However, the hazard ratios between high and low HMO markets are closer to 
one in this period than in the previous period, except for birthing room and sports medicine where the hazard ratios remain to be statistically significantly below one. By 2000-2003, the hazard rates of shutting down safety net services are quite comparable between high and low HMO markets, except for trauma center: hospitals in high (medium) HMO markets are 2.5 (1.62) times more likely to shut down trauma centers than those in low HMO markets. In the same period, hospitals in medium HMO markets all have higher risk of shutting down safety net services than those in low HMO markets. Among profitable services, all hazard ratios are above one for medium and high HMO markets in 2000-2003, except for maternity care. In particular, the risks of hospitals in high HMO markets shutting down birthing room, women's health center and child wellness center are 1.57, 1.54 and 2.21 times higher, respectively, than those in low HMO markets.

To help visualize the HMO effects in Table 2, I graph the predicted survival probability of all hospital services in Figure 4. Specifically, the survival curves in Figure 4 represent the predicted survival probability of each service holding all characteristics (except for HMO) at their average value. Therefore the gap between the survival curves in low and high HMO markets can be solely attributed to the differences in HMO penetration. The kinks at $t_{5}$ and $t_{10}$ reflect the interaction period effects. For clarity, I omit the survival curves of medium HMO markets. Figure 4A shows that trauma center has much lower survival rates in high HMO markets than in low HMO markets. Figure 4B shows that except for maternity care, all other profitable services experience a lower survival rate in high HMO markets especially in 2000s.

\section{Effect of For-Profit Share of HMO on the Hazard of Service Exit}

My next set of analyses investigates the effect of for-profit HMO on the hazard of service 
shut down. As described in section 3, I analyze low, medium, and high HMO markets separately. Table 3 shows the effect of for-profit HMO on service exit rate assuming no change in hazard ratios over time. For sake of brevity, I omit medium HMO markets results in this table but can provide the numbers upon request. The top panel shows that for low HMO markets, there is no statistically significant difference in service exit hazard between hospitals in low and high for-profit HMO markets, regardless service profitability. The bottom panel presents the hazard ratio for high HMO markets. Among safety net services, only inpatient substance abuse service receives a statistically significant hazard ratio: hospitals in markets with high share of for-profit HMO plans are 1.85 times more likely to shut down inpatient substance abuse service than those in markets with low share of for-profit plans. Note that the magnitude of hazard ratio of outpatient substance abuse service is also relatively high (1.65) but the smaller sample size prevents me from obtaining a more precise standard error estimate. Among profitable services, high FP HMO market is associated with higher risk of shutting down birthing room and sports medicine (hazard ratios are 1.8 and 2.06, respectively).

Table 4 shows the hazard ratio of for-profit HMO effect by three periods. Again I only focus on low and high HMO markets. In low HMO markets, the hazard rates of service exit in markets with medium and high for-profit HMO in general tend to be lower than those in markets with low for-profit share of HMO during 1990-1994. The hazard of shutting down substance abuse and HIV/AIDS services increases over time. By 2000-2003, the hazard of shutting down inpatient substance abuse and HIV/AIDS services are 2 times higher in markets with high forprofit HMO share compared to those in markets with low for-profit HMO market share. Among profitable services, hazard ratio also increases by 2000-2003, but none of the results are statistically significant. The magnitude of the hazard ratio for birthing room and sports medicine 
is not small (1.86 and 1.40 for high for-profit HMO markets, respectively), but the smaller sample size prevents me from obtaining more precise estimates.

In high HMO markets, I observe more pronounced period differential of the for-profit HMO effect on service shut down. Among safety net services, hospitals in high for-profit HMO markets in general have higher hazard of shutting down services than those in low for-profit HMO markets, especially toward the later period. For example, the risks of shutting down substance abuse service (both inpatient and outpatient) between hospitals in high and low forprofit HMO markets are comparable in 1990-1994. By 2000-2003, hospitals in high for-profit HMO markets are more than 2 times likely to shut down these services than those in low forprofit HMO markets. Likewise for trauma center where the corresponding hazard ratio increases from 0.56 in 1990-1994 to 3.42 in 200-2003. Among profitable care, the hazard ratio of shutting down services are all below one for high for-profit HMO markets for 1990-1994. For maternity care and child wellness center, the hazard ratios remain close to one by 2000-2003, but for the other profitable services, the hazard ratios increase substantially. The hazard of shutting down birthing room, women's health center, and sports medicine are 3.05, 2.09, and 4.06, respectively, times higher in markets with high for-profit share of HMO than in markets with low for-profit share of HMO.

Figure 5 presents the predicted survival rate of safety net services. Similar to Figure 4, these are predicted cumulative survival probability assuming all other characteristics take on the average value. Figure 5A and 5B show the predicted survival curves for low HMO markets and high HMO markets, respectively. In both markets, substance abuse care services have much lower survival rates in markets with high for-profit share of $\mathrm{HMO}$, but the survival gap is bigger in high HMO markets. Trauma center in markets with high for-profit share of HMO also suffers 
a lower survival rate in the later period. Figure 6 shows the same information for profitable services. Figure 6A shows that in low HMO areas, there is little difference between high and low for-profit HMO markets. Figure 6B shows that in high HMO areas, except for maternity care, all other profitable services have much lower survival rate in markets with high for-profit share of HMO than markets with low for-profit share.

\section{Sensitivity Analyses}

As an alternative proxy for actual HMO growth, I also experiment with using peak year HMO penetration instead of the average HMO penetration over this period to classify hospitals into different $\mathrm{HMO}$ and for-profit $\mathrm{HMO}$ markets. The magnitude of the hazard ratios is very similar whether I use peak year or average HMO penetration rates (results available upon request). This result is not surprising given that the correlation between these two measures is over 0.90 .

I am also concerned with whether the decision to offer and shut down a service depends on the availability of such a service in the hospital market in prior years. The hospital competition measure is not service-specific, and a hospital would be less likely to shut down a service if historically it is the only provider of that service in that particular market. In another sensitivity analysis, I include number of hospitals offering a given service within 15 -mile radius in the baseline (i.e., 1990 for all services except for HIV/AIDS service and child wellness center whose baseline is 1994). It turned out that the hazard ratio of the baseline service variable is very close to one across all services, and therefore the effects of HMO and for-profit HMO stay the same (results available upon request).

I use Cox proportional hazard model instead of Prentice-Gloeckler proportional hazard 
model to allow for more flexible specification of the baseline hazard and sensitivity analyses. In Table 5, I compare the results between the two approaches. As the comparison shows, the coefficients and their significance are extremely similar.

The hazard of service shut down might be different between hospitals that were in continuous operation and those that were short-lived. I conduct a sensitivity analysis where I restrict the sample to only hospitals that are in operation continuously between 1991 and $2003 .^{5}$ I lose about a quarter of the hospitals when restricting the sample this way. However, I only lose $10-20 \%$ of the observations (depending on the service) because not all excluded hospitals offer a given service. I found the hazard ratios are magnified in some cases and similar in others, but the qualitative results remain the same (Table 6). For example, when using the whole sample, the hazard ratios for maternity care in 1990-1994 period are 0.52 and 0.59 for medium and high HMO markets. In the restricted sample, the corresponding hazard ratios are 0.24 and 0.38 . The hazard ratios for women's health center are 1.59 and 1.52 in 2000-2003 for medium and high HMO markets in the whole sample, and the corresponding hazard ratios are 1.78 and 1.62 in the restricted sample.

In the next set of analyses, I investigate whether the results are driven by differences between early and late adopters of the services. If the timing of adoption varies systematically across the three levels of HMO penetration, it would also likely affect the duration of the service. In this case, the results of the HMO effects on service shut down would be confounded with the timing of service adoption. While prior studies showed that higher HMO penetration is associated with slower rate of technology adoption (Cutler and Sheiner 1997), it is not clear whether the same would apply to safety net or public health services. In this sensitivity analysis, I include an

\footnotetext{
${ }^{5}$ In my main model, if a hospital closed or dropped out of the AHA survey, it would be censored in the proportional hazard model.
} 
"early adopter" indicator that takes on the value of one if hospitals have already adopted a given service by the first year of observation. As Table 7 shows, the hazard ratios on medium and high HMO markets remain very similar to the original specification and all the conclusions remain the same. Not surprisingly, early adopter has a lower hazard rate of shutting down any given service - this is analogous to the regression toward the mean phenomenon.

Another potential source of bias in the coefficient estimates might come from unobserved heterogeneity across MSA markets. If HMO plans selectively enter markets that have high propensity to shut down unprofitable services for reasons not captured in the model, my results would overstate the effect of high HMO on service shut down. One way to test this hypothesis is by modeling the unobserved heterogeneity as a multiplicative additional source of error in the shut down equation (Baker and Phibbs 2001; Cleves et al 2004). In other words, the hazard function in eq (1) above is modified as follows for hospital $i$ offering service $j$ in market $m$ :

$$
\lambda_{i j m}(t)=\exp \left(x_{i j} \beta_{j}\right) \lambda_{0 j}(t) \alpha_{m}
$$

where $\alpha_{\mathrm{m}}$ varies by MSA. One can think of this approach as a random-effects Cox proportional hazard model. For computational convenience, $\alpha_{\mathrm{m}}$ is assumed to be gamma distributed with mean of one and variance of $\theta$. The estimate of $\theta$ allows me to test the existence of unobserved heterogeneity: if $\theta$ is zero, the random-effect Cox model reverts to the standard Cox model. I show the value of $\theta$ and the log-likelihood test for unobserved heterogeneity at the bottom of Table 2. In most cases, we cannot reject the null hypothesis that there is no unobserved heterogeneity across markets. In two services where there is evidence of unobserved heterogeneity (maternity care and birthing room), the coefficients on our key variables are very similar to Table 2 and all our conclusions remain the same (coefficient results available upon request). 
Lastly, I consider the implication of using only HMO penetration measure when there are other types of managed care that also compete for provider business. In this set of analyses, I use a noisy overall managed care penetration to classify MSAs instead of using the more reliable HMO penetration. This managed care penetration measure includes enrollment from HMO and PPO (preferred provider organization), the second dominant form of health plans. As discussed in Section 3, there is little reliable data on PPO penetration. I have 1992, 1995, and 2003 PPO penetration from two different sources (see Shen and Melnick 2004 for more details). I construct the average overall managed care penetration over this period in the following steps. First, I obtain the average PPO penetration across the three available years for each MSA. Second, I add this average PPO penetration to the average HMO penetration I used earlier to obtain the average overall managed care penetration. ${ }^{6}$ The mean average managed care penetration rate is 54 percent. I divide hospitals into low, medium, and high managed care markets where the cutoff points of managed care penetration rates are $0-40 \%, 40-60 \%$, and $>60 \%$. Percent of hospitals that fall into each managed care category is 25 percent, 48 percent, and 28 percent.

Table 8 shows that for safety net services, the results are remarkably similar to the main model: hospitals in low managed care markets started out having the highest hazard of shutting down safety net services in 1990-1994, but the hazard rates increased over time in medium and high managed care markets. Like the main analysis, by 2000-2003, trauma center stood out as having the highest hazard ratio (close to 2) in medium and high managed care markets compared to low managed care markets. Among profitable services, results are also similar except for child wellness center: the hazard ratio in 2000-2003 is much lower for the comparison between high and low managed care markets. The similar results between using HMO and using overall

\footnotetext{
${ }^{6}$ I consider this managed care measure noisier than the HMO measure because I only have 3 years of PPO data to summarize the PPO market and the data are less reliable than HMO data (personal communication with Interstudy representative).
} 
managed care penetration to classify markets are not too surprising, since markets with higher HMO activities also tend to have higher penetration of PPO. Among hospitals that were classified in low HMO markets, only 4 hospitals got classified into high managed care markets when we add PPO and HMO information together; among hospitals that were classified as in high HMO markets, only 3 were classified into low managed care markets.

\section{Discussions}

This paper begins with the research question, does higher HMO penetration lead to higher risks of shutting down specialized services in hospitals? I started out with two competing hypotheses. If economies of scale is the key to reduce hospital cost, then we might see safety services being shut down to make room for more profitable services when facing financial pressure from HMO plans. If economies of scope is the key to attract demand from health plans, then we might see hospitals adding new services to complement its existing ones and observe no difference in exit rates across HMO markets. The empirical results, however, do not fit neatly into either hypothesis, as I find the risk of shut down shifts over time. Specifically, hospitals in medium and high HMO markets started out having lower hazard of shutting down services in 1990-1994 (especially in the area of profitable services) than those in low HMO markets, but their hazard rates increased over time. By 2000-2003, hospitals in medium and high HMO markets ended up with higher risk of shutting down profitable services than those in low HMO markets and comparable hazard rates of shutting down safety net services except for trauma center.

One possible explanation is that economy of scope was at work during the early 1990s, when hospitals in higher HMO markets would try to attract the booming HMO industry by keeping a 
diverse set of services, while hospitals in low HMO markets have less incentive to do so. Resource allocation is another possible explanation. During the early 1990s, hospitals in low HMO markets had higher propensity to adopt expensive cardiac and imaging technology, and might have to shut down safety net and public health services to make resources available to adopt those technologies. As HMO expanded in the second half of 1990s and the financial pressure from HMO grew stronger, hospitals in high HMO markets responded to such financial pressure by shutting down selective services, as well as being slow adopters of expensive technology. This explanation is consistent with what's being observed in the health care technology adoption literature. Prior studies generally found that higher HMO penetration is associated with slower technology adoption rates in the 1990s due to the increasing financial pressure from HMO. It is worth noting that when comparing high and low HMO markets, I observe higher probability of shut down among profitable services than among safety net services in the $2000-2003$ period. Perhaps community pressure keeps safety net services from being shut down in high HMO markets.

The managed care backlash in the 2000s is supposed to alleviate the financial pressure from HMOs on providers (Shen and Melnick 2006). However, I find the survival gap between low and high HMO markets to be larger in this period than in the 1990s. This is likely due to the fact that the magnitude of retrenchment is not uniform across the three types of markets. The average HMO growth rate between $1999-2003$ is $-20 \%$ for low HMO markets but only $-8 \%$ and $-11 \%$ for medium and high HMO markets. The increasing gap in financial pressure from HMO between the high and low markets might contribute to the increasing hazard of service shut down in high HMO markets after 2000.

My second research question explores whether the risks of shutting down services vary by 
whether hospitals operate in HMO markets that are predominantly for-profit. I do not find the hazard of shutting down services to differ by levels of for-profit HMO share in low HMO markets except for HIV/AIDS and inpatient substance abuse services. I find higher for-profit share of HMO to be associated with higher hazard of service exit for half of the services examined in high HMO markets, and the hazard ratios are the highest in 2000-2003. This is consistent with the microeconomics framework which suggests that a predominantly for-profit HMO markets is likely to exert greater financial pressure than a HMO market that is predominantly not-for-profit. A prior study found that hospitals in high for-profit HMO markets have slower cost growth than those in low for-profit HMO markets, and the difference is especially evident in high HMO markets (Shen and Melnick 2004). Taking together, this would suggest that some of the cost growth reduction might be achieved by shutting down services, and that hospitals in predominantly for-profit HMO markets experience greater HMO financial pressure than those in predominantly not-for-profit HMO markets. Like results to the first research question, the higher hazard ratios of exit in for-profit HMO markets do not occur only in safety net services, but also in profitable services.

Although not the focus of this paper, I want to highlight the role of hospital ownership in affecting service shut down. I find that the hazard rate of shutting down profitable services is comparable among not-for-profit, for-profit, and government hospitals, while the hazard of shutting down safety net services is the highest in for-profit hospitals and lowest in government hospitals. This finding is consistent with the common theoretical framework that frequently posits that not-for-profit firms have an objective function different from that of profit maximization and that government hospitals often serve as last resort hospitals (Sloan 2000). An important area I did not explore is the potential spillover effect of hospital for-profit 
ownership. As Kessler and McClellan (2002) pointed out, spillover effects might be much more important than the direct ownership effect, since for-profit hospitals account for less than 20 percent of the market share. Exploring this spillover effect on service shut down should be an interesting and important future work.

These results are robust under different sensitivity analyses, and the overall conclusion remains the same when I use a noisier overall managed care penetration measure in place of the more accurately measured HMO penetration rates. However, readers should keep in mind several limitations in the empirical methods. First, the service measures are self-reported by hospitals and the attrition rate of AHA survey has deteriorated over the years. While such a noisy dependent variable is a cause of concern, as long as the reporting errors and attrition rates do not vary systematically across the HMO markets, my estimates should not be biased. Second, although HMOs continue to be the biggest type of managed care plans, its dominance has diminished over the years as more PPO and plans of other arrangements entered the market. Even though results remain robust when I use a noisy managed care measure that includes HMO and PPO, that measure still does not capture all types of managed care plans. Third, to the extent that service adoption and shut-down decisions are endogenously related to HMO growth, I mitigate this concern by using average HMO penetration over the period to classify MSAs instead of using the actual HMO penetration for each year. In addition, the coefficients on the key variables are very stable even when I assume there exists unobserved heterogeneity across markets. However, some omitted variable bias might still remain under this approach.

With these caveats in mind, these results suggest that most safety net services are not in worse danger of being shut down in high HMO markets. This is certainly comforting news for low-income population, as they are the major users of these services. But we should not ignore 
the fact that although the hazard of shutting down safety services are not different across the HMO markets in the current environment, the overall survival rate of these services, with emergency department being the exception, are substantially lower than that of more profitable services. The high exit rates of substance abuse and HIV/AIDS services are problematic given the nature of the treatment: disrupting substance abuse care, for example, could have much worse consequence on the affected patient population than shutting down sports medicine. For services where I observe a substantially higher rate of exit among hospitals in high HMO markets in the current environment (such as trauma center, women's health center, and child wellness center), future work should consider the patient welfare consequences and policy implications of exodus of these services.

The results also highlight the role of ownership in service provision. Through a combination of conversions by not-for-profit health plans to for-profit status, acquisitions of not-for-profit's by for-profit companies and internal growth, the share of total HMO enrollment in for-profit health plans is now over $60 \%$ in many parts of the US. Results from this paper suggest that hospitals in those markets have higher risk of shutting down safety net and public health services. Moreover, for-profit hospitals have higher propensity to shut down unprofitable services. The potential disruption of care is an important aspect state regulators should take into consideration when evaluating ownership conversions in health care markets. 


\section{Reference}

Baker, L.C., 1997. The effect of HMOs on fee-for-service health care expenditures: evidence from Medicare. Journal of Health Economics 16, 453-481.

Baker LC and Wheeler, SK. 1998. Managed care and technology diffusion: the case of MRI. Health Affairs 17(5): 195-207.

Baker LC. 2001. Managed care and technology adoption in health care: evidence from magnetic resonance imaging. Journal of Health Economics. 20(3):395-421.

Baker LC, Phibbs CS. 2002. Managed care, technology adoption, and health care: the adoption of neonatal intensive care. Rand Journal of Economics. 33(3):524-48.

Baker LC, and Spetz J. 1998. Managed care and medical technology growth. In A.M. Garber, ed., Frontiers in Health Policy Research, No. 2. Cambridge, MA: MIT Press.

Bamezai A, Zwanziger J, Melnick GA, and Mann JM. 1999. Price competition and hospital cost growth in the United States (1989-1994). Health Economics, 8(3): 233-43.

Blendon, RJ, M Brodie, J M Benson, D E Altman, L Levitt, T Hoff, and L Hugick. 1998. Understanding the managed care backlash. Health Affairs, July/August 1998; 17(4): 80-94.

Cleves, MA, Gould, WW, and Gutierrez, RG. 2004. An Introduction to Survival Analysis Using Stata. College Station, TX: A Stata Corporation.

Cox, D.R., 1972. Regression models and life tables. Journal of the Royal Statistical Society 34, 187-220.

Cutler, DM. and McClellan, M. 1996. The determinants of technological change in heart attack treatment. NBER Working Paper 5751.

Cutler, DM and Sheiner, L. 1997. Managed care and the growth of medical expenditures. NBER Working Paper \#6140.

Draper, DA. RE Hurley, CS Lesser, and BC Strunk. 2002. The changing face of managed care. Health Affairs, January/February 2002; 21(1): 11-23.

Eggleston, K., Lau, J., Schmid, C., Chan, J., and Shen, Y. 2006. Systematic review of hospital ownership and quality of care: What explains the different results in the literature? $N B E R$ working paper \#12241.

Gaskin, DJ. 1999. Safety Net Hospitals: Essential Providers of Public Health and Specialty Services. New York: Commonwealth Fund.

Gaskin, D.J. and J. Hadley. 1997. The impact of HMO penetration on the rate of hospital cost inflation, 1985-1993. Inquiry 34 (Fall 1997): 205-216.

Greene, W. 1997. Econometric Analysis. Upper Saddle River, NJ: Prentice Hall. 
Hirth, RA. 1999. Consumer information and competition between nonprofit and for-profit nursing homes. Journal of Health Economics, 18, pp. 219-40.

Horwitz, JR. 2005. Making profits and providing care: comparing nonprofit, for-profit, and government hospitals. Health Affairs 24(3):790-801.

Hymen, DA. and Kovacic, WE. 2004. Monopoly, monopsony, and market definition: an antitrust perspective on market concentration among health insurers. Health Affairs, 23(6): 25-28.

Kessler, DP., McClellan, MB. 2002. The effects of hospital ownership on medical productivity. RAND Journal of Economics 33, no. 3: 488-506.

Marquis, M.S., Rogowski, J.A. and J.J. Escarce. 2004. The managed care backlash: did consumers vote with their feet? Inquiry, 41 (winter 2004/2005): 376-390.

Mays GP, Hurley RE, Grossman JM. 2003. An empty toolbox? Changes in health plans' approaches for managing costs and care. Health Serv Res. 2003 Feb;38(1 Pt 2):375-93.

Mays GP, Claxton G, White J. 2004. Managed care rebound? Recent changes in health plans' cost containment strategies. Health Affairs, 2004 Jul-Dec;Suppl Web Exclusives:W4-42736.

Morrisey, MA. 2001. Competition in hospital and health insurance markets: a review and research agenda. Health Services Research 36(1, Part II): 191-221.

Prentice, R. and Gloeckler, L. 1978. Regression analysis of grouped survival data with application to breast cancer data. Biometrics, Vol. 34, 57-67.

Robinson, JC. 2001. The end of managed care. JAMA. 2001 May 23-30;285(20):2622-8.

Shen, Y. and Melnick, G.A. 2004. The effects of HMO ownership on hospital costs and revenues: Is there a difference between for-profit and not-for-profit plan? Inquiry 41(3): 255-267.

Shen, Y. and Melnick, G.A. 2006. Is managed care still an effective cost containment device? Manuscript.

Shen, Y., Eggleston, K., Schmid, C. and Lau, J. 2005. Hospital ownership and financial performance: A quantitative research review. NBER Working Paper \# 11662.

Sloan, FA. 2000. Not-for-profit ownership and hospital behavior. Handbook of Health Economics. 1B. 1141-1174.

Swartz, K. 1999. The death of managed care as we know it. J Health Polit Policy Law. 1999 Oct;24(5):1201-5.

Zuckerman S, Bazzoli G, Davidoff A, LoSasso A. 2001 How did safety-net hospitals cope in the 1990s? Health Affairs 20(4): 159-168. 
Figure 1. Trend of Overall HMO Penetration: 1990-2003

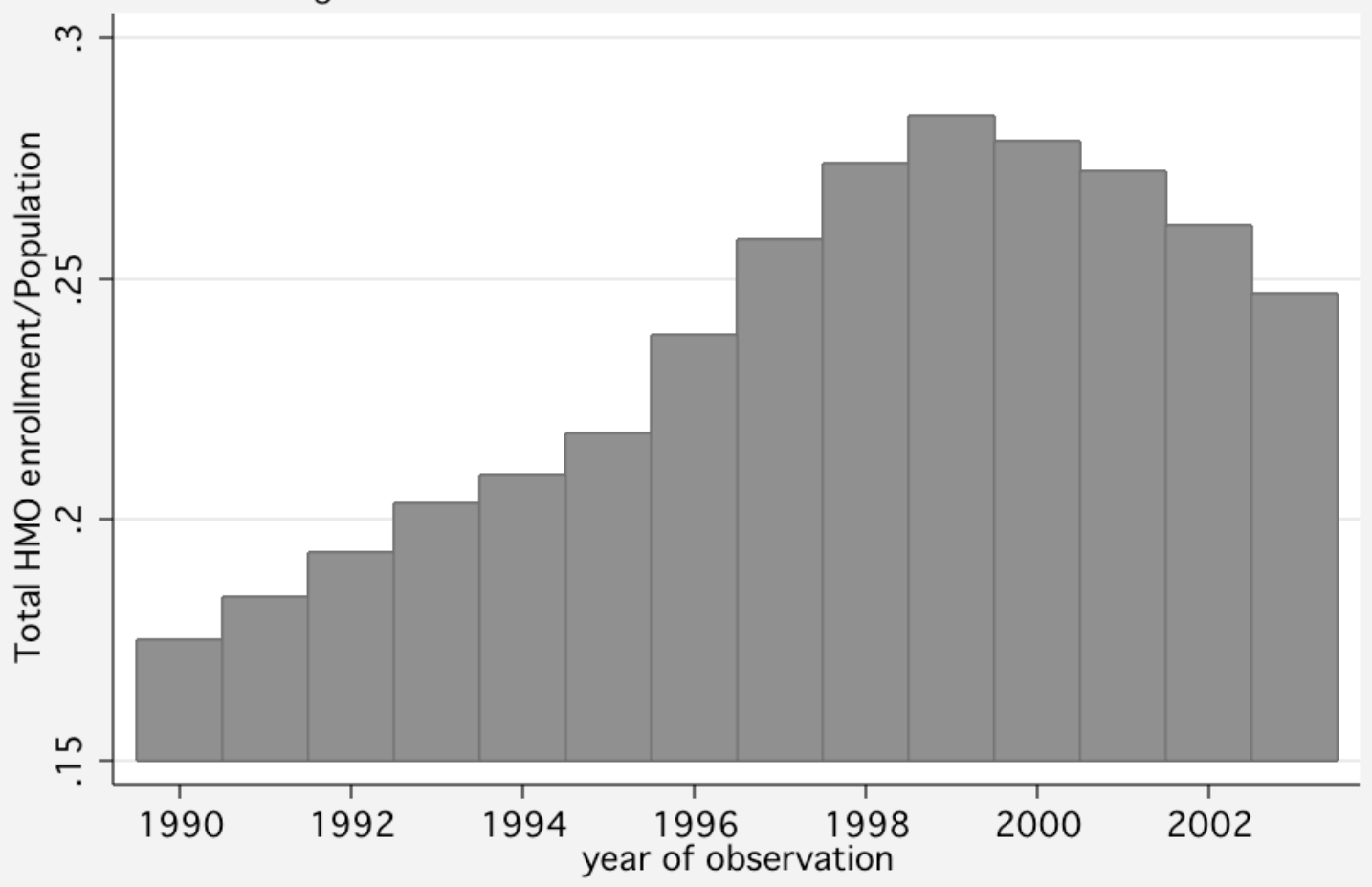

Source: Laurence Baker/Interstudy

Figure 2. Trend of For-Profit Share of HMO Enrollment By HMO Penetration Levels: 1994-2003

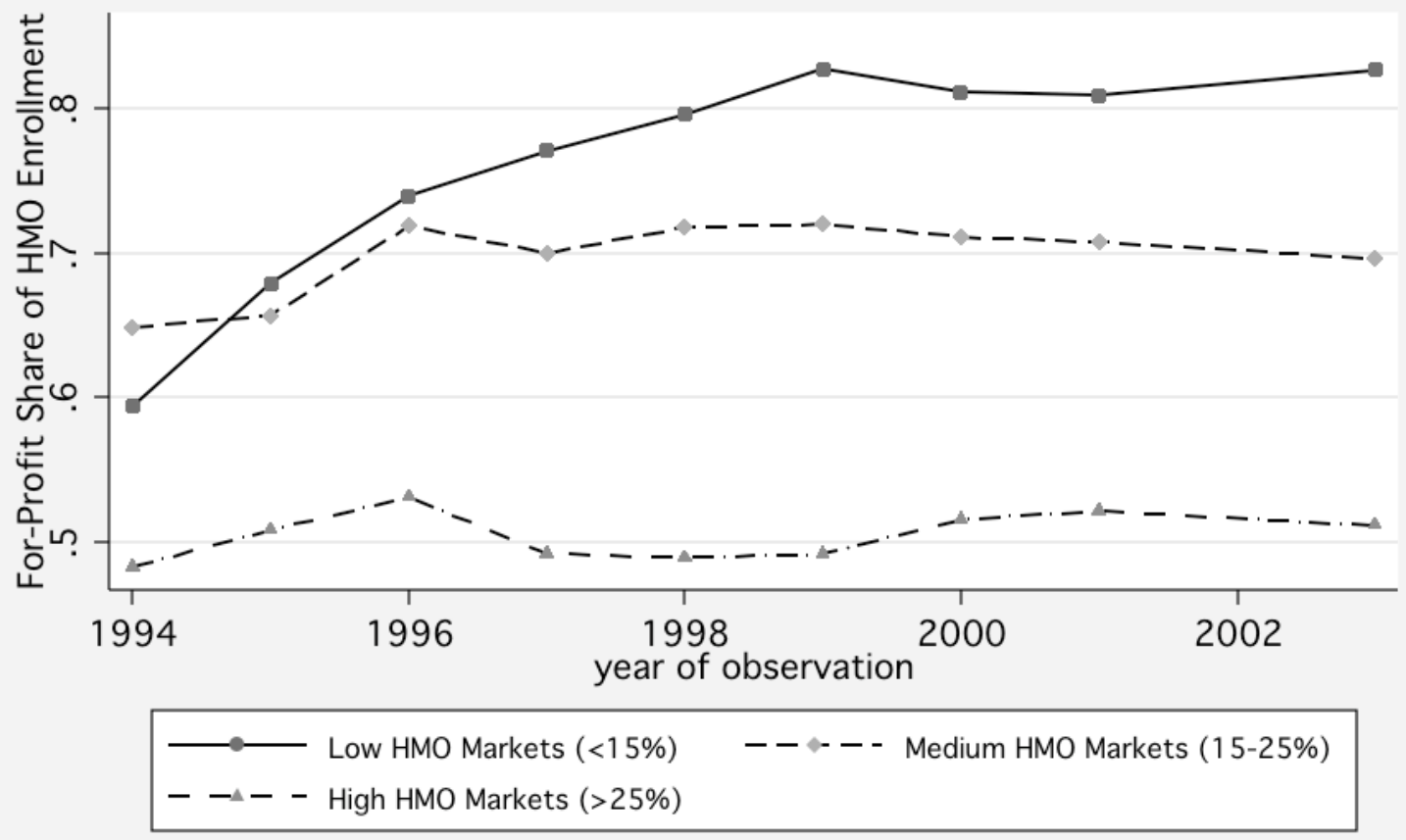

Source: Interstudy

Note: HMO ownership information is not available before 1994 
Figure 3. Cumulative Survival Probability of Hospital Services

3A. Safety Net Services
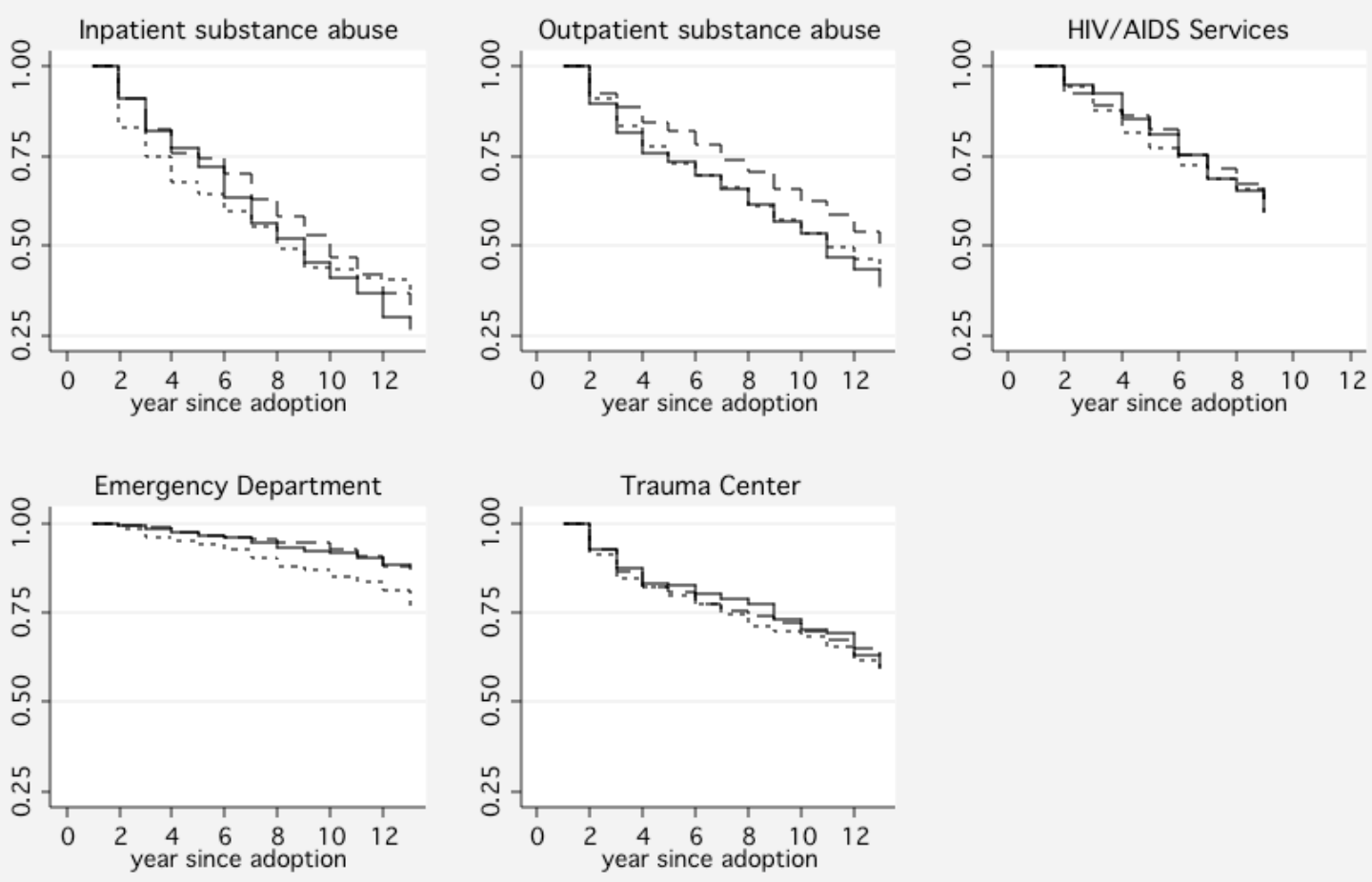

3B. Profitable Services
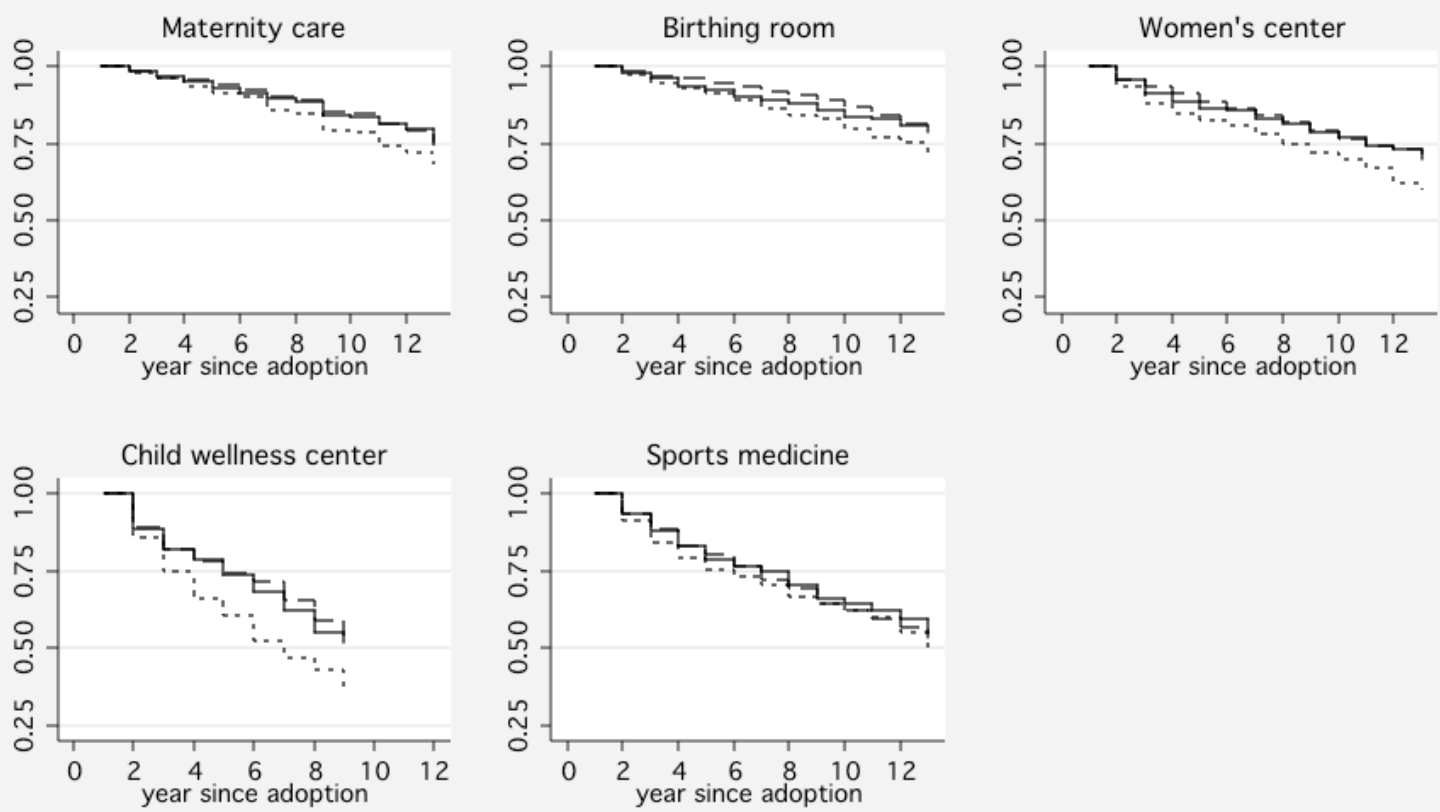

Low HMO markets (<15\%)

Medium HMO markets (15-25\%)

High HMO markets (>25\%) 
Figure 4. Predicted Survival Probability of Hospital Services

\section{A. Safety Net Services}
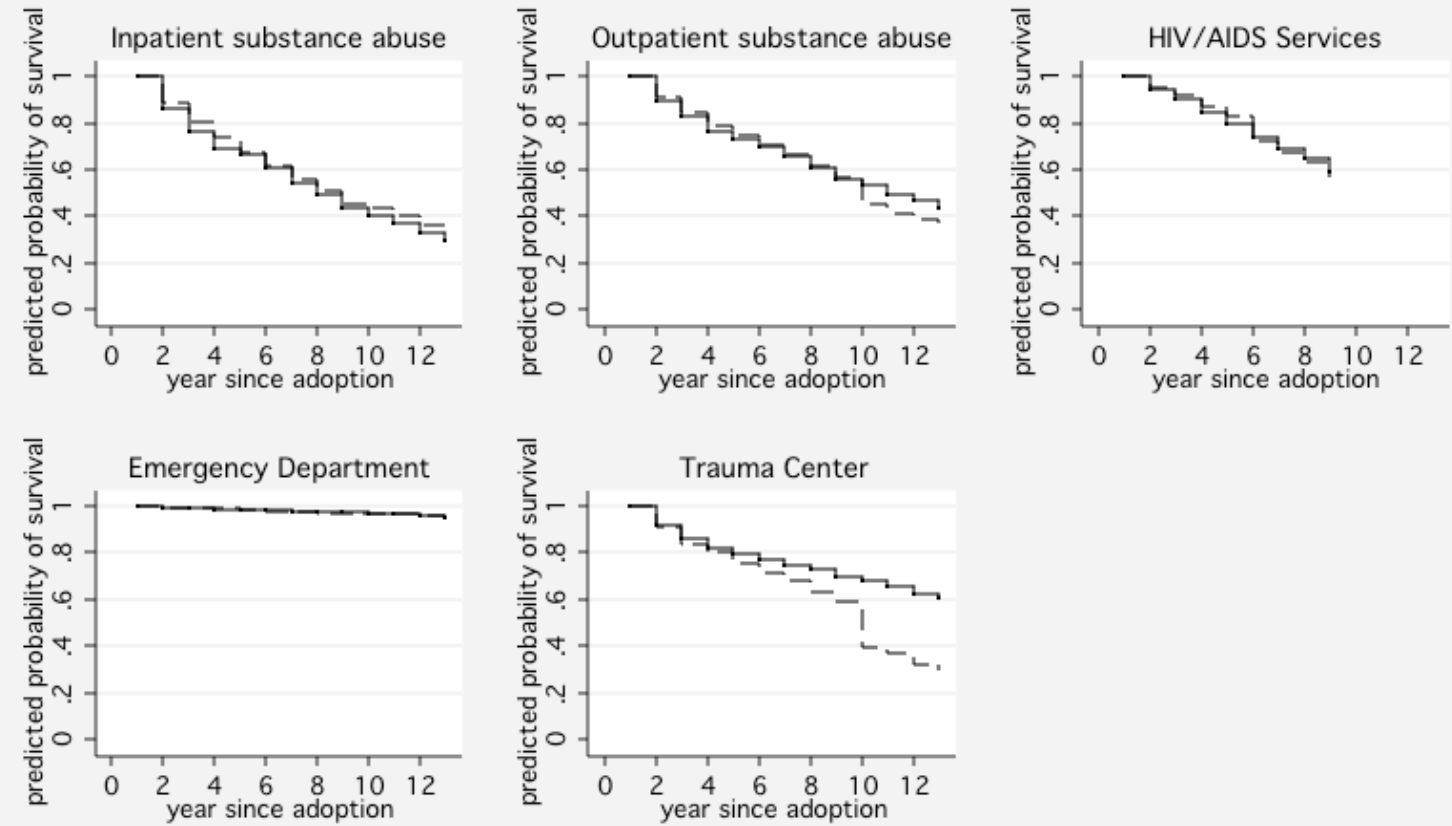

\section{low HMO markets} - - - - high HMO markets

4B. Profitable Services
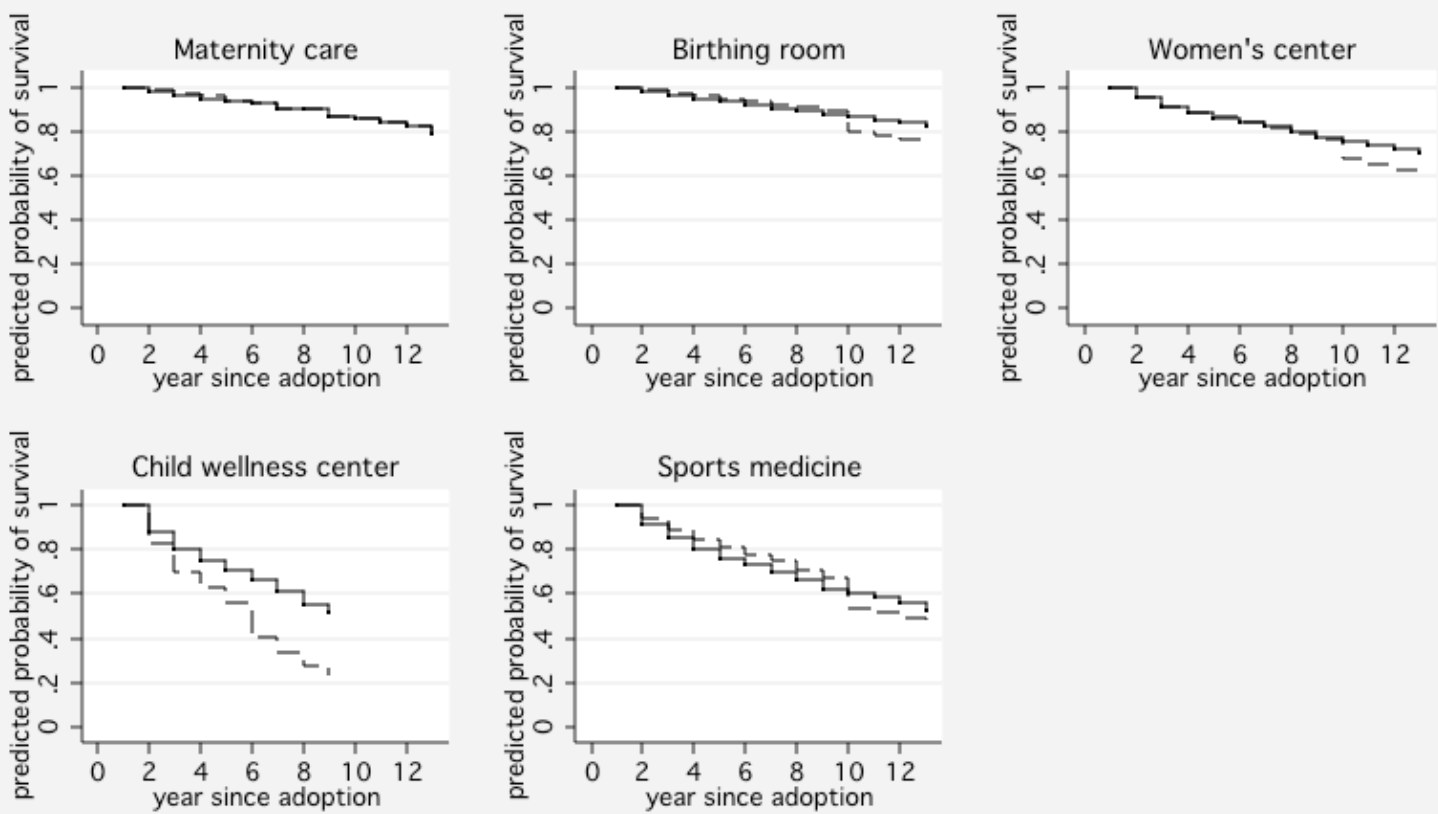

\section{- low HMO markets - - - - - high HMO markets}

Note: Based on regression coefficients from bottom panel of Table 2 Holding all other variables at their average values 
Figure 5. Predicted Survival Probability of Safety Net Services

\section{A. Low HMO Markets}
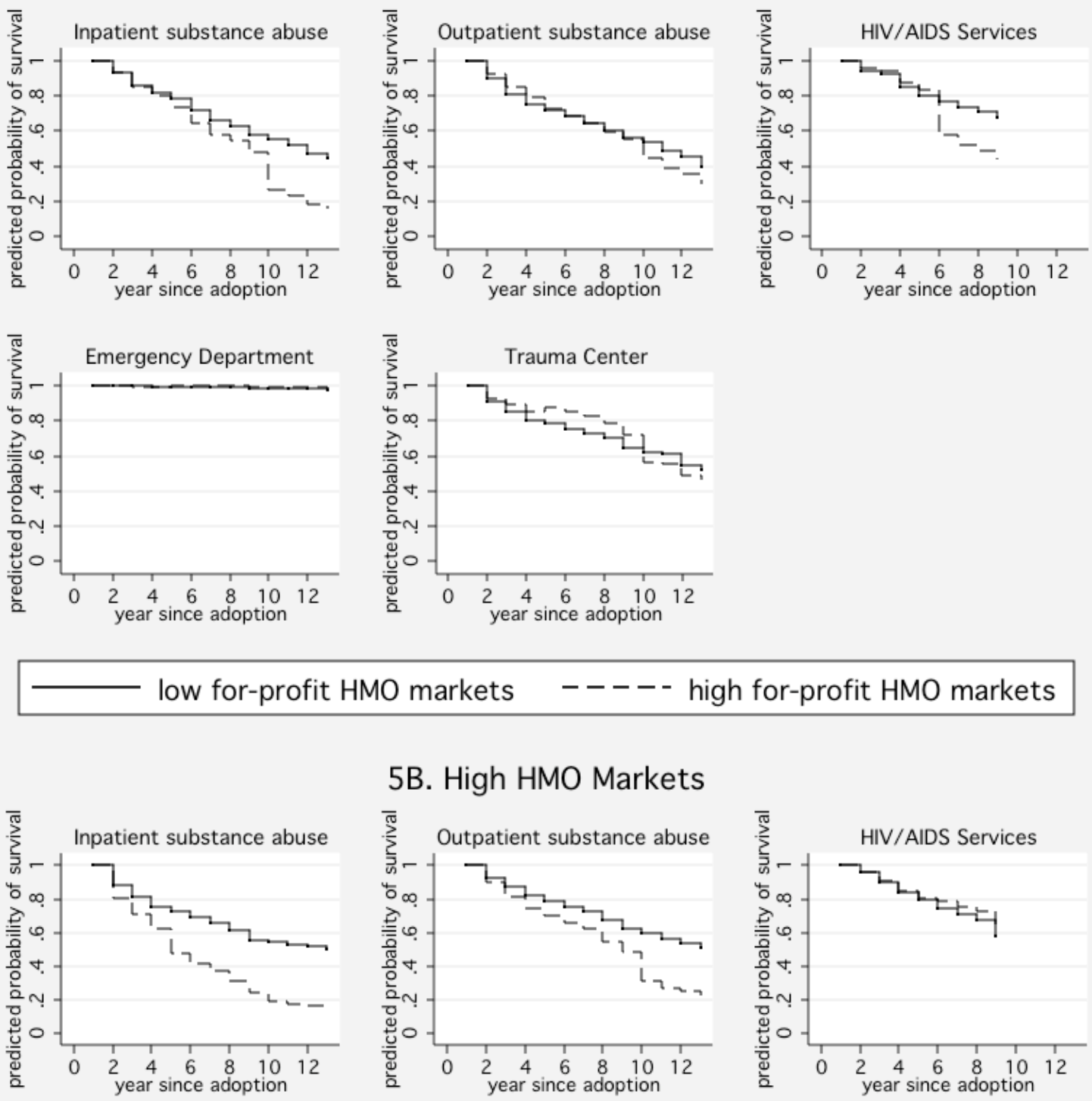

\section{B. High HMO Markets}
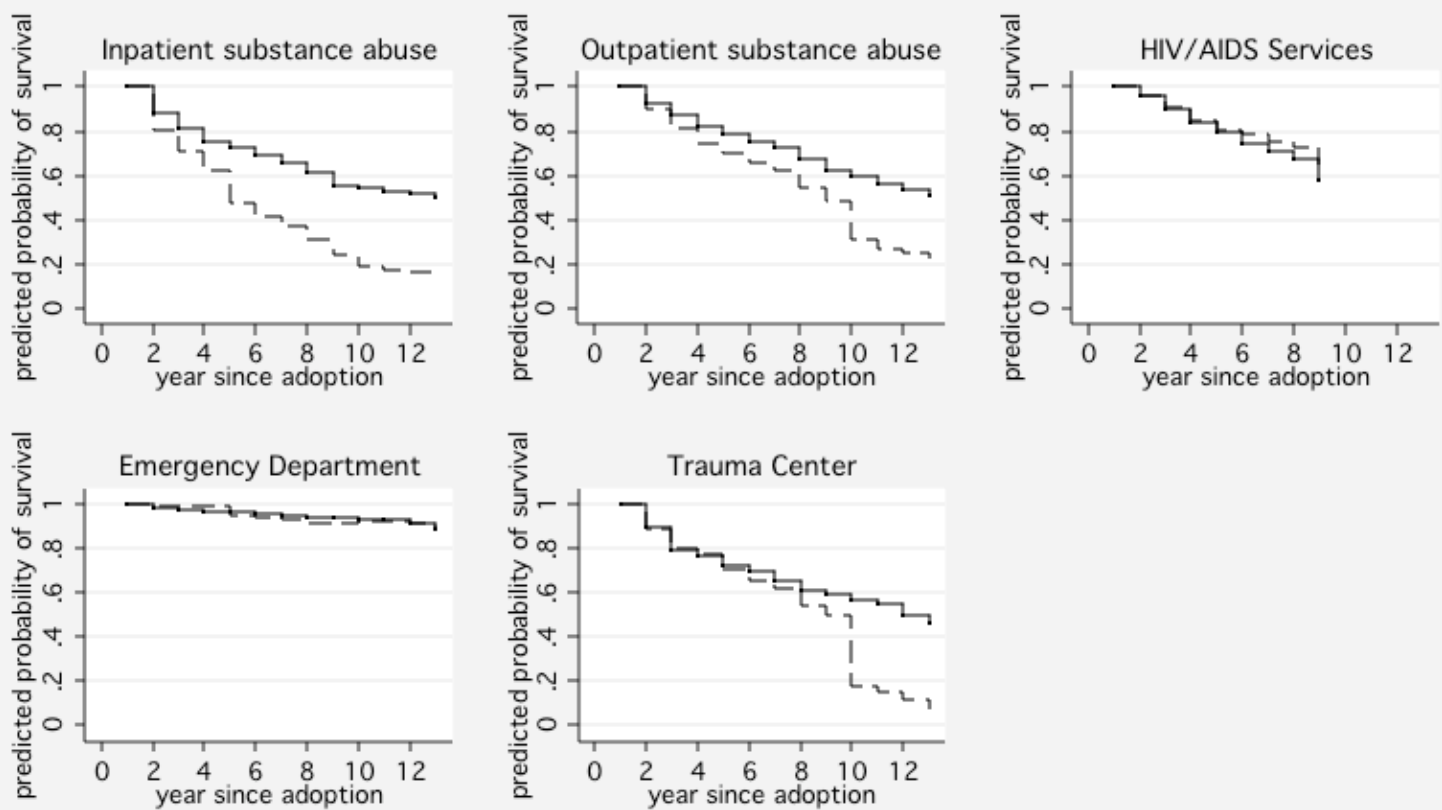

\section{low for-profit HMO markets}

high for-profit HMO markets

Note: Based on regression coefficients from Table 4 Holding all other variables at their average values 
Figure 6. Predicted Survival Probability of Profitable Services

6A. Low HMO Markets
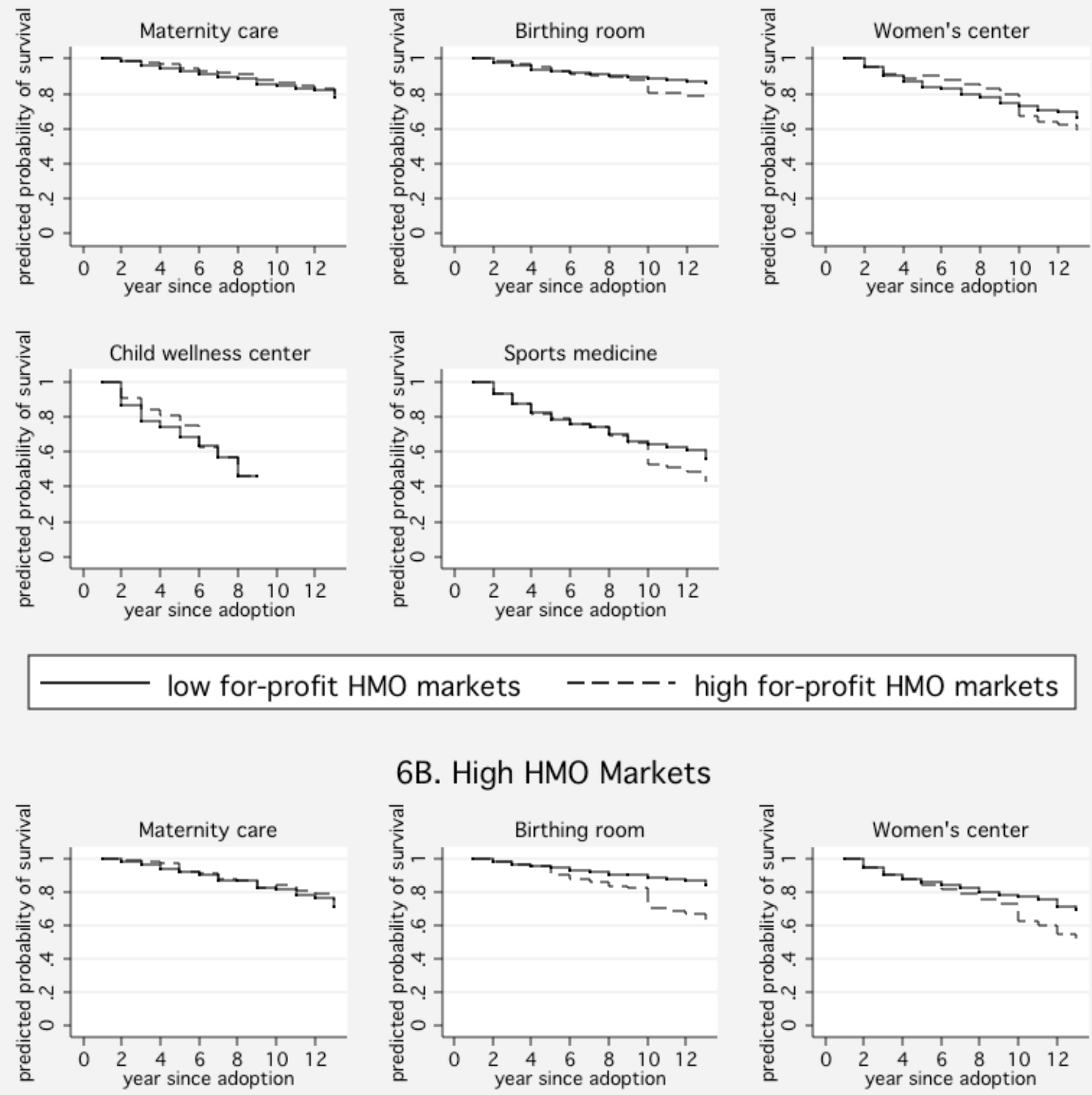

\section{B. High HMO Markets}
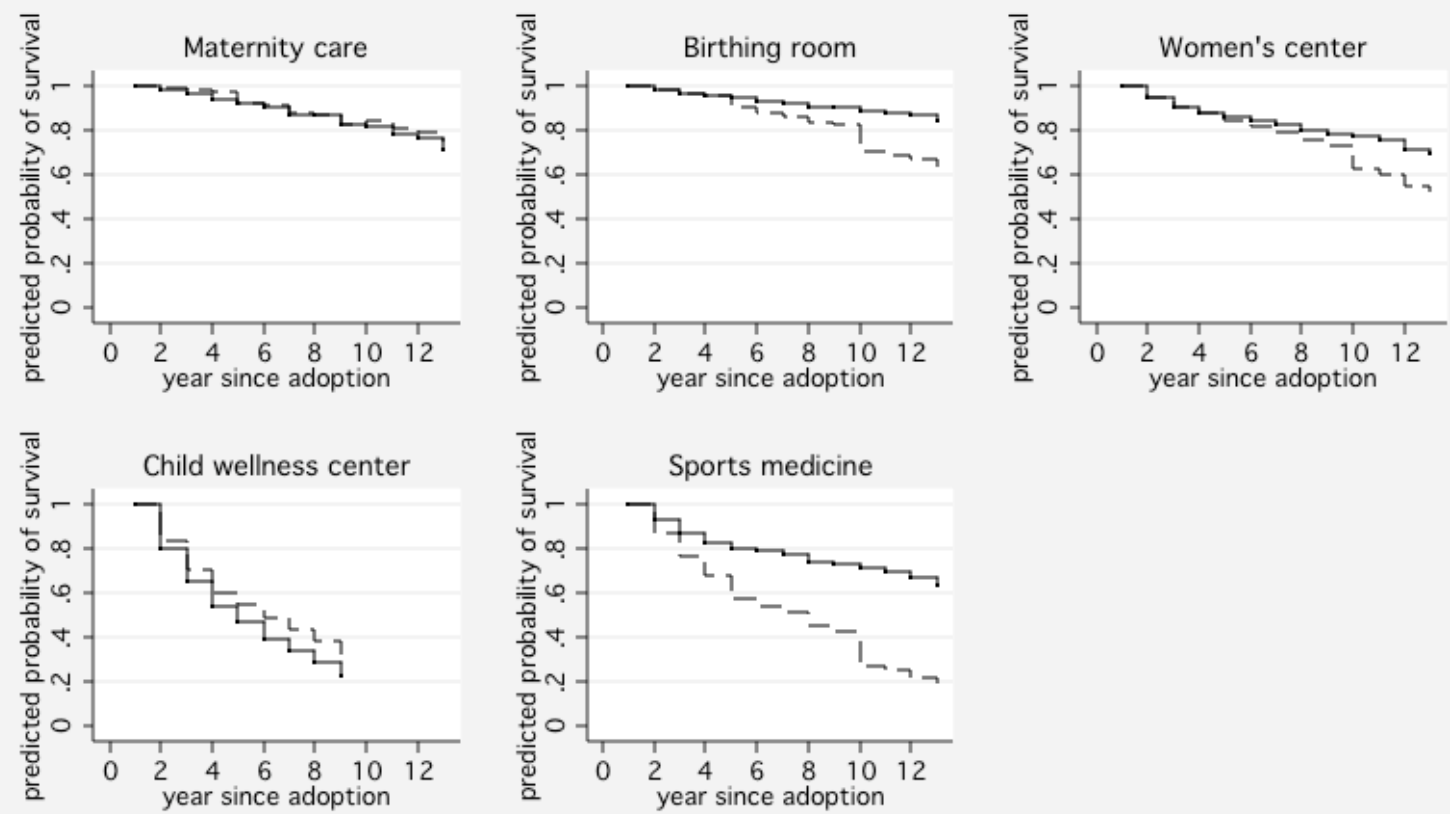

\section{— low for-profit HMO markets ----- high for-profit HMO markets}

Note: Based on regression coefficients from Table 4 Holding all other variables at their average values 
Table 1. Hospital and Market Characteristics between 1990-2003 by HMO Penetration Levels

\begin{tabular}{|c|c|c|c|c|c|c|}
\hline \multirow[t]{2}{*}{ 1990-2003 Average } & \multicolumn{2}{|c|}{ Low HMO markets } & \multicolumn{2}{|c|}{ Medium HMO markets } & \multicolumn{2}{|c|}{ High HMO Markets } \\
\hline & Mean & $\underline{\mathrm{SD}}$ & Mean & $\underline{\mathrm{SD}}$ & Mean & $\underline{\mathrm{SD}}$ \\
\hline Not-for-profit & $54 \%$ & $4 \overline{1 \%}$ & $75 \%$ & $30 \%$ & $71 \%$ & $32 \%$ \\
\hline For-profit & $24 \%$ & $42 \%$ & $14 \%$ & $35 \%$ & $17 \%$ & $38 \%$ \\
\hline Government & $22 \%$ & $41 \%$ & $10 \%$ & $30 \%$ & $12 \%$ & $32 \%$ \\
\hline $\begin{array}{l}\text { Ownership converted during 1990- } \\
2003\end{array}$ & $21 \%$ & $41 \%$ & $16 \%$ & $37 \%$ & $20 \%$ & $40 \%$ \\
\hline Teaching & $7 \%$ & $25 \%$ & $13 \%$ & $33 \%$ & $12 \%$ & $32 \%$ \\
\hline System membership & $59 \%$ & $47 \%$ & $59 \%$ & $46 \%$ & $64 \%$ & $44 \%$ \\
\hline Herfindahl index & 0.34 & 0.10 & 0.29 & 0.10 & 0.26 & 0.09 \\
\hline Casemix index & 1.37 & 0.24 & 1.37 & 0.22 & 1.37 & 0.22 \\
\hline Total discharges & 9038 & 8232 & 10299 & 8776 & 11356 & 157459 \\
\hline Total outpatients & 113858 & 137965 & 143499 & 162495 & 124930 & 147526 \\
\hline Wage index & 0.94 & 0.12 & 1.07 & 0.18 & 1.14 & 0.17 \\
\hline MSA population & 605,688 & 851,993 & $2,427,901$ & $2,509,900$ & $3,121,351$ & $2,670,361$ \\
\hline Per capita income & 21785 & 5695 & 26586 & 9455 & 26565 & 7859 \\
\hline $\begin{array}{l}\text { Percent FP hospitals within } 15 \text { mile } \\
\text { radius }\end{array}$ & $15 \%$ & $20 \%$ & $10 \%$ & $15 \%$ & $14 \%$ & $18 \%$ \\
\hline $\begin{array}{l}\text { Percent government hospitals within } \\
15 \text {-mile radius }\end{array}$ & $10 \%$ & $15 \%$ & $6 \%$ & $10 \%$ & $7 \%$ & $11 \%$ \\
\hline Number of observations & 9783 & & 12673 & & 10704 & \\
\hline
\end{tabular}


Table 2. The Effect of Overall HMO Penetration on Hazard Ratio of Service Exit

\begin{tabular}{|c|c|c|c|c|c|c|c|c|c|c|}
\hline Hazard ratio (SE) & $\begin{array}{l}\text { Inpatient } \\
\text { substance abuse }\end{array}$ & $\begin{array}{l}\text { Outpatient } \\
\text { substance abuse }\end{array}$ & $\begin{array}{l}\text { HIV/AIDS } \\
\text { services }\end{array}$ & $\begin{array}{l}\text { Emergency } \\
\text { department }\end{array}$ & $\begin{array}{l}\text { Trauma } \\
\text { center }\end{array}$ & $\begin{array}{l}\text { Maternity } \\
\text { care }\end{array}$ & Birthing room & Women's center & $\begin{array}{l}\text { Child wellness } \\
\text { center }\end{array}$ & $\begin{array}{l}\text { Sports } \\
\text { medicine }\end{array}$ \\
\hline \multicolumn{11}{|l|}{ Overall } \\
\hline $\begin{array}{l}\text { Low HMO Markets } \\
\text { (reference group) }\end{array}$ & 1.0 & 1.0 & 1.0 & 1.0 & 1.0 & 1.0 & 1.0 & 1.0 & 1.0 & 1.0 \\
\hline Medium HMO markets & $\begin{array}{c}0.89 \\
(0.12)\end{array}$ & $\begin{array}{c}0.89 \\
(0.10)\end{array}$ & $\begin{array}{c}0.86 \\
(0.12)\end{array}$ & $\begin{array}{l}0.80 \\
(0.15)\end{array}$ & $\begin{array}{l}1.11 \\
(0.16)\end{array}$ & $\begin{array}{c}0.78 \\
(0.13)\end{array}$ & $\begin{array}{l}0.73+ \\
(0.14)\end{array}$ & $\begin{array}{c}0.85 \\
(0.14)\end{array}$ & $\begin{array}{l}1.16 \\
(0.21)\end{array}$ & $\begin{array}{c}0.95 \\
(0.13)\end{array}$ \\
\hline High HMO markets & $\begin{array}{c}0.89 \\
(0.14) \\
\end{array}$ & $\begin{array}{c}0.96 \\
(0.12) \\
\end{array}$ & $\begin{array}{c}0.94 \\
(0.14) \\
\end{array}$ & $\begin{array}{c}1.06 \\
(0.19) \\
\end{array}$ & $\begin{array}{l}1.48^{*} \\
(0.26) \\
\end{array}$ & $\begin{array}{c}0.88 \\
(0.16) \\
\end{array}$ & $\begin{array}{c}0.93 \\
(0.17) \\
\end{array}$ & $\begin{array}{c}1.01 \\
(0.15) \\
\end{array}$ & $\begin{array}{l}1.74 * * \\
(0.32) \\
\end{array}$ & $\begin{array}{c}0.81 \\
(0.13) \\
\end{array}$ \\
\hline \multicolumn{11}{|l|}{ By Periods } \\
\hline Medium HMO markets & $\begin{array}{l}0.65^{*} \\
(0.14)\end{array}$ & $\begin{array}{l}0.58^{*} \\
(0.12)\end{array}$ & $\begin{array}{l}-- \\
--\end{array}$ & $\begin{array}{c}0.65 \\
(0.20)\end{array}$ & $\begin{array}{c}0.80 \\
(0.24)\end{array}$ & $\begin{array}{l}0.52 * \\
(0.14)\end{array}$ & $\begin{array}{c}0.49 * * \\
(0.13)\end{array}$ & $\begin{array}{l}0.52 * \\
(0.13)\end{array}$ & $\begin{array}{l}-- \\
--\end{array}$ & $\begin{array}{c}0.84 \\
(0.17)\end{array}$ \\
\hline High HMO markets & $\begin{array}{c}0.84 \\
(0.18)\end{array}$ & $\begin{array}{c}0.78 \\
(0.14)\end{array}$ & -- & $\begin{array}{c}0.81 \\
(0.26)\end{array}$ & $\begin{array}{c}0.69 \\
(0.22)\end{array}$ & $\begin{array}{c}0.66 \\
(0.21)\end{array}$ & $\begin{array}{l}0.66+ \\
(0.16)\end{array}$ & $\begin{array}{c}0.79 \\
(0.19)\end{array}$ & $\begin{array}{l}-- \\
--\end{array}$ & $\begin{array}{l}0.60^{*} \\
(0.13)\end{array}$ \\
\hline \multicolumn{11}{|l|}{ 1995-1999 } \\
\hline Medium HMO markets & $\begin{array}{c}0.83 \\
(0.14)\end{array}$ & $\begin{array}{c}0.81 \\
(0.12)\end{array}$ & $\begin{array}{l}0.64 * \\
(0.13)\end{array}$ & $\begin{array}{l}0.50 * \\
(0.15)\end{array}$ & $\begin{array}{l}0.71+ \\
(0.14)\end{array}$ & $\begin{array}{l}0.65^{*} \\
(0.13)\end{array}$ & $\begin{array}{c}0.46 * * \\
(0.12)\end{array}$ & $\begin{array}{c}0.54 * * \\
(0.11)\end{array}$ & $\begin{array}{c}0.87 \\
(0.22)\end{array}$ & $\begin{array}{l}0.74+ \\
(0.13)\end{array}$ \\
\hline High HMO markets & $\begin{array}{c}0.94 \\
(0.18)\end{array}$ & $\begin{array}{c}0.88 \\
(0.15)\end{array}$ & $\begin{array}{c}0.81 \\
(0.17)\end{array}$ & $\begin{array}{c}1.18 \\
(0.26)\end{array}$ & $\begin{array}{c}0.99 \\
(0.23)\end{array}$ & $\begin{array}{c}0.93 \\
(0.19)\end{array}$ & $\begin{array}{l}0.70+ \\
(0.15)\end{array}$ & $\begin{array}{c}0.82 \\
(0.14)\end{array}$ & $\begin{array}{c}1.22 \\
(0.25)\end{array}$ & $\begin{array}{l}0.63^{*} \\
(0.13)\end{array}$ \\
\hline \multicolumn{11}{|l|}{ 2000-2003 } \\
\hline Medium HMO markets & $\begin{array}{c}1.30 \\
(0.23)\end{array}$ & $\begin{array}{l}1.41+ \\
(0.25)\end{array}$ & $\begin{array}{c}1.08 \\
(0.20)\end{array}$ & $\begin{array}{c}1.32 \\
(0.34)\end{array}$ & $\begin{array}{l}1.62 * * \\
(0.27)\end{array}$ & $\begin{array}{c}1.13 \\
(0.25)\end{array}$ & $\begin{array}{c}1.41 \\
(0.36)\end{array}$ & $\begin{array}{l}1.61 * \\
(0.31)\end{array}$ & $\begin{array}{l}1.47^{*} \\
(0.28)\end{array}$ & $\begin{array}{l}1.41+ \\
(0.25)\end{array}$ \\
\hline High HMO markets & $\begin{array}{c}0.89 \\
(0.22)\end{array}$ & $\begin{array}{c}1.28 \\
(0.21)\end{array}$ & $\begin{array}{c}1.07 \\
(0.20)\end{array}$ & $\begin{array}{c}1.13 \\
(0.29)\end{array}$ & $\begin{array}{c}2.50 * * \\
(0.51)\end{array}$ & $\begin{array}{c}0.96 \\
(0.22)\end{array}$ & $\begin{array}{l}1.57+ \\
(0.39)\end{array}$ & $\begin{array}{l}1.54 * \\
(0.31)\end{array}$ & $\begin{array}{c}2.21 * * \\
(0.46)\end{array}$ & $\begin{array}{c}1.29 \\
(0.23)\end{array}$ \\
\hline \multicolumn{11}{|c|}{ Testing for $\mathrm{H}_{0}$ : no unobserved heterogeneity across MSA markets (theta=0) } \\
\hline estimated theta & 0.058 & $<0.001$ & $<0.001$ & 0.039 & 0.28 & 0.087 & 0.073 & $<0.001$ & $<0.001$ & 0.039 \\
\hline $\begin{array}{l}\text { probability of not } \\
\text { rejecting } \mathrm{H}_{0}\end{array}$ & 0.10 & 0.50 & 0.50 & 0.17 & 0.29 & 0.02 & 0.05 & 0.50 & 0.50 & 0.17 \\
\hline Observations & 5707 & 8713 & 8462 & 26497 & 8172 & 20412 & 20732 & 14801 & 4087 & 10537 \\
\hline
\end{tabular}

Robust standard errors in parentheses

+ significant at $10 \% ; *$ significant at $5 \% ; * *$ significant at $1 \%$

Baseline hazard rate varies by 4 Census regions

Complete regression results are available in Appendix 
Table 3. The Effect of For-Profit HMO on Hazard Ratio of Service Exit

\begin{tabular}{|c|c|c|c|c|c|c|c|c|c|c|}
\hline Hazard ratio (SE) & $\begin{array}{l}\text { Inpatient } \\
\text { substance abuse }\end{array}$ & $\begin{array}{l}\text { Outpatient } \\
\text { substance abuse }\end{array}$ & $\begin{array}{l}\text { HIV/AIDS } \\
\text { services }\end{array}$ & $\begin{array}{l}\text { Emergency } \\
\text { department }\end{array}$ & $\begin{array}{l}\text { Trauma } \\
\text { center }\end{array}$ & \begin{tabular}{|l|} 
Maternity \\
care
\end{tabular} & $\begin{array}{l}\text { Birthing } \\
\text { room }\end{array}$ & $\begin{array}{l}\text { Women's } \\
\text { center }\end{array}$ & $\begin{array}{l}\text { Child wellness } \\
\text { center }\end{array}$ & $\begin{array}{l}\text { Sports } \\
\text { medicine }\end{array}$ \\
\hline \multicolumn{11}{|l|}{$\underline{\text { Low HMO Markets }}$} \\
\hline $\begin{array}{l}\text { Low FP share of HMO } \\
\text { (reference group) }\end{array}$ & 1.0 & 1.0 & 1.0 & 1.0 & 1.0 & 1.0 & 1.0 & 1.0 & 1.0 & 1.0 \\
\hline Medium FP share of HMO & $\begin{array}{c}1.27 \\
(0.42)\end{array}$ & $\begin{array}{c}1.12 \\
(0.36)\end{array}$ & $\begin{array}{c}0.90 \\
(0.29)\end{array}$ & $\begin{array}{c}0.77 \\
(0.26)\end{array}$ & $\begin{array}{c}0.82 \\
(0.35)\end{array}$ & $\begin{array}{c}0.81 \\
(0.39)\end{array}$ & $\begin{array}{c}1.04 \\
(0.41)\end{array}$ & $\begin{array}{c}0.66 \\
(0.24)\end{array}$ & $\begin{array}{c}0.84 \\
(0.34)\end{array}$ & $\begin{array}{l}1.15 \\
(0.35)\end{array}$ \\
\hline High FP share of HMO & $\begin{array}{c}1.33 \\
(0.42) \\
\end{array}$ & $\begin{array}{c}0.96 \\
(0.32) \\
\end{array}$ & $\begin{array}{c}1.11 \\
(0.32)\end{array}$ & $\begin{array}{c}0.55 \\
(0.21) \\
\end{array}$ & $\begin{array}{c}0.86 \\
(0.34) \\
\end{array}$ & $\begin{array}{c}0.74 \\
(0.33)\end{array}$ & $\begin{array}{c}1.03 \\
(0.39) \\
\end{array}$ & $\begin{array}{c}0.86 \\
(0.29) \\
\end{array}$ & $\begin{array}{c}0.75 \\
(0.29) \\
\end{array}$ & $\begin{array}{c}0.99 \\
(0.29) \\
\end{array}$ \\
\hline Observations & 1706 & 2227 & 2779 & 7653 & 2522 & 5988 & 6107 & 4391 & 1054 & 3202 \\
\hline \multicolumn{11}{|l|}{ High HMO Markets } \\
\hline $\begin{array}{l}\text { Low FP share of HMO } \\
\text { (reference group) }\end{array}$ & 1.0 & 1.0 & 1.0 & 1.0 & 1.0 & 1.0 & 1.0 & 1.0 & 1.0 & 1.0 \\
\hline Medium FP share of HMO & $\begin{array}{c}0.88 \\
(0.26)\end{array}$ & $\begin{array}{c}1.12 \\
(0.31)\end{array}$ & $\begin{array}{c}0.95 \\
(0.24)\end{array}$ & $\begin{array}{c}0.73 \\
(0.26)\end{array}$ & $\begin{array}{c}0.75 \\
(0.24)\end{array}$ & $\begin{array}{c}0.69 \\
(0.16)\end{array}$ & $\begin{array}{c}1.24 \\
(0.29)\end{array}$ & $\begin{array}{c}0.87 \\
(0.22)\end{array}$ & $\begin{array}{c}1.14 \\
(0.29)\end{array}$ & $\begin{array}{c}1.07 \\
(0.33)\end{array}$ \\
\hline High FP share of HMO & $\begin{array}{c}1.85^{*} \\
(0.46)\end{array}$ & $\begin{array}{c}1.65 \\
(0.53) \\
\end{array}$ & $\begin{array}{c}0.84 \\
(0.16) \\
\end{array}$ & $\begin{array}{c}1.04 \\
(0.26)\end{array}$ & $\begin{array}{c}1.46 \\
(0.35) \\
\end{array}$ & $\begin{array}{c}0.90 \\
(0.26) \\
\end{array}$ & $\begin{array}{c}1.80 * * \\
(0.37)\end{array}$ & $\begin{array}{c}1.11 \\
(0.21) \\
\end{array}$ & $\begin{array}{c}0.80 \\
(0.23) \\
\end{array}$ & $\begin{array}{l}2.06^{*} \\
(0.64)\end{array}$ \\
\hline Observations & 1505 & 2479 & 2519 & 8044 & 2220 & 6016 & 6078 & 4308 & 1118 & 2867 \\
\hline
\end{tabular}

Robust standard errors in parentheses

+ significant at $10 \% ; *$ significant at $5 \% ; * *$ significant at $1 \%$ 
Table 4. The Effect of For-Profit HMO On Hazard Rate of Service Exit

\begin{tabular}{|c|c|c|c|c|c|c|c|c|c|c|}
\hline Hazard ratio (SE) & $\begin{array}{l}\text { Inpatient } \\
\text { substance abuse }\end{array}$ & $\begin{array}{l}\text { Outpatient } \\
\text { substance abuse }\end{array}$ & $\begin{array}{l}\text { HIV/AIDS } \\
\text { services }\end{array}$ & $\begin{array}{l}\text { Emergency } \\
\text { department }\end{array}$ & $\begin{array}{l}\text { Trauma } \\
\text { center }\end{array}$ & $\begin{array}{l}\text { Maternity } \\
\text { care }\end{array}$ & $\begin{array}{l}\text { Birthing } \\
\text { room }\end{array}$ & $\begin{array}{l}\text { Women's } \\
\text { center }\end{array}$ & $\begin{array}{l}\text { Child wellness } \\
\text { center }\end{array}$ & $\begin{array}{l}\text { Sports } \\
\text { medicine }\end{array}$ \\
\hline \multicolumn{11}{|l|}{ Low HMO Markets } \\
\hline \multicolumn{11}{|l|}{$1990-1994$} \\
\hline Medium FP HMO share & $\begin{array}{c}0.74 \\
(0.40)\end{array}$ & $\begin{array}{c}0.77 \\
(0.37)\end{array}$ & $\begin{array}{l}-- \\
--\end{array}$ & $\begin{array}{l}0.24+ \\
(0.20)\end{array}$ & $\begin{array}{c}0.95 \\
(0.72)\end{array}$ & $\begin{array}{c}0.80 \\
(0.58)\end{array}$ & $\begin{array}{l}0.27+ \\
(0.20)\end{array}$ & $\begin{array}{c}0.61 \\
(0.40)\end{array}$ & $\begin{array}{l}-- \\
--\end{array}$ & $\begin{array}{c}0.36 \\
(0.27)\end{array}$ \\
\hline High FP HMO share & $\begin{array}{c}0.85 \\
(0.35)\end{array}$ & $\begin{array}{l}0.53+ \\
(0.20)\end{array}$ & $\begin{array}{l}-- \\
--\end{array}$ & $\begin{array}{c}1.32 \\
(0.81)\end{array}$ & $\begin{array}{c}0.99 \\
(0.59)\end{array}$ & $\begin{array}{c}0.59 \\
(0.39)\end{array}$ & $\begin{array}{c}0.60 \\
(0.28)\end{array}$ & $\begin{array}{c}1.03 \\
(0.45)\end{array}$ & -- & $\begin{array}{c}0.99 \\
(0.39)\end{array}$ \\
\hline \multicolumn{11}{|l|}{ 1995-1999 } \\
\hline Medium FP HMO share & $\begin{array}{c}1.38 \\
(0.52)\end{array}$ & $\begin{array}{c}0.93 \\
(0.35)\end{array}$ & $\begin{array}{c}0.84 \\
(0.36)\end{array}$ & $\begin{array}{c}0.74 \\
(0.35)\end{array}$ & $\begin{array}{l}0.55 \\
(0.27)\end{array}$ & $\begin{array}{l}0.76 \\
(0.36)\end{array}$ & $\begin{array}{l}1.31 \\
(0.57)\end{array}$ & $\begin{array}{c}0.55 \\
(0.27)\end{array}$ & $\begin{array}{c}0.77 \\
(0.34)\end{array}$ & $\begin{array}{c}1.22 \\
(0.42)\end{array}$ \\
\hline High FP HMO share & $\begin{array}{c}1.10 \\
(0.36)\end{array}$ & $\begin{array}{c}0.92 \\
(0.32)\end{array}$ & $\begin{array}{c}0.83 \\
(0.32)\end{array}$ & $\begin{array}{l}0.32 * \\
(0.15)\end{array}$ & $\begin{array}{c}0.43 \\
(0.26)\end{array}$ & $\begin{array}{c}0.69 \\
(0.32)\end{array}$ & $\begin{array}{c}0.93 \\
(0.40)\end{array}$ & $\begin{array}{l}0.41^{*} \\
(0.16)\end{array}$ & $\begin{array}{c}0.48 \\
(0.23)\end{array}$ & $\begin{array}{c}0.74 \\
(0.23)\end{array}$ \\
\hline \multicolumn{11}{|l|}{$2000-2003$} \\
\hline Medium FP HMO share & $\begin{array}{c}1.64 \\
(0.72)\end{array}$ & $\begin{array}{c}1.86 \\
(0.82)\end{array}$ & $\begin{array}{c}2.27 \\
(1.14)\end{array}$ & $\begin{array}{c}1.13 \\
(0.50)\end{array}$ & $\begin{array}{c}0.96 \\
(0.47)\end{array}$ & $\begin{array}{c}0.87 \\
(0.50)\end{array}$ & $\begin{array}{c}1.61 \\
(0.88)\end{array}$ & $\begin{array}{c}0.80 \\
(0.35)\end{array}$ & $\begin{array}{c}1.02 \\
(0.48)\end{array}$ & $\begin{array}{c}1.86 \\
(0.71)\end{array}$ \\
\hline High FP HMO share & $\begin{array}{l}2.37^{*} \\
(0.83)\end{array}$ & $\begin{array}{c}1.62 \\
(0.67) \\
\end{array}$ & $\begin{array}{l}2.17+ \\
(0.91)\end{array}$ & $\begin{array}{c}0.71 \\
(0.32) \\
\end{array}$ & $\begin{array}{c}1.03 \\
(0.42) \\
\end{array}$ & $\begin{array}{c}0.88 \\
(0.41) \\
\end{array}$ & $\begin{array}{c}1.86 \\
(0.81) \\
\end{array}$ & $\begin{array}{c}1.36 \\
(0.52) \\
\end{array}$ & $\begin{array}{c}1.01 \\
(0.40)\end{array}$ & $\begin{array}{c}1.40 \\
(0.45)\end{array}$ \\
\hline \multicolumn{11}{|l|}{ High HMO Markets } \\
\hline \multicolumn{11}{|l|}{$\underline{1990-1994}$} \\
\hline Medium FP HMO share & 0.88 & 1.15 & -- & 0.62 & 0.54 & 0.55 & 1.19 & $0.43 *$ & -- & 0.60 \\
\hline High FP HMO share & $\begin{array}{c}(0.26) \\
1.25 \\
(0.65)\end{array}$ & $\begin{array}{c}(0.36) \\
1.35 \\
(0.44)\end{array}$ & $\begin{array}{l}-- \\
-- \\
--\end{array}$ & $\begin{array}{c}(0.27) \\
0.18 * * \\
(0.05)\end{array}$ & $\begin{array}{c}(0.25) \\
0.56 \\
(0.42)\end{array}$ & $\begin{array}{c}(0.23) \\
0.22 \\
(0.27)\end{array}$ & $\begin{array}{c}(0.31) \\
0.77 \\
(0.39)\end{array}$ & $\begin{array}{l}(0.15) \\
0.49 * \\
(0.16)\end{array}$ & $\begin{array}{l}-- \\
-- \\
--\end{array}$ & $\begin{array}{c}(0.26) \\
0.97 \\
(0.45)\end{array}$ \\
\hline \multicolumn{11}{|l|}{$1995-1999$} \\
\hline$\overline{\text { Medium FP HMO share }}$ & $\begin{array}{c}0.63 \\
(0.21)\end{array}$ & $\begin{array}{c}0.87 \\
(0.28)\end{array}$ & $\begin{array}{c}0.65 \\
(0.26)\end{array}$ & $\begin{array}{c}0.68 \\
(0.26)\end{array}$ & $\begin{array}{l}0.37 * \\
(0.19)\end{array}$ & $\begin{array}{c}0.75 \\
(0.23)\end{array}$ & $\begin{array}{c}0.65 \\
(0.20)\end{array}$ & $\begin{array}{c}0.67 \\
(0.19)\end{array}$ & $\begin{array}{l}0.54+ \\
(0.18)\end{array}$ & $\begin{array}{c}0.79 \\
(0.27)\end{array}$ \\
\hline High FP HMO share & $\begin{array}{l}2.24^{*} \\
(0.74)\end{array}$ & $\begin{array}{c}1.40 \\
(0.76)\end{array}$ & $\begin{array}{c}1.10 \\
(0.30)\end{array}$ & $\begin{array}{c}1.40 \\
(0.41)\end{array}$ & $\begin{array}{c}0.81 \\
(0.22)\end{array}$ & $\begin{array}{c}1.11 \\
(0.43)\end{array}$ & $\begin{array}{l}1.65^{*} \\
(0.36)\end{array}$ & $\begin{array}{c}0.99 \\
(0.28)\end{array}$ & $\begin{array}{c}0.86 \\
(0.28)\end{array}$ & $\begin{array}{l}2.02+ \\
(0.79)\end{array}$ \\
\hline \multicolumn{11}{|l|}{ 2000-2003 } \\
\hline Medium FP HMO share & $\begin{array}{c}1.84 \\
(0.87)\end{array}$ & $\begin{array}{c}1.61 \\
(0.53)\end{array}$ & $\begin{array}{c}1.17 \\
(0.41)\end{array}$ & $\begin{array}{c}0.94 \\
(0.36)\end{array}$ & $\begin{array}{c}1.34 \\
(0.45)\end{array}$ & $\begin{array}{c}0.68 \\
(0.21)\end{array}$ & $\begin{array}{l}2.25 * \\
(0.72)\end{array}$ & $\begin{array}{c}1.61 \\
(0.50)\end{array}$ & $\begin{array}{l}1.86^{*} \\
(0.52)\end{array}$ & $\begin{array}{c}2.18^{* *} \\
(0.63)\end{array}$ \\
\hline High FP HMO share & $\begin{array}{l}2.68+ \\
(1.38)\end{array}$ & $\begin{array}{c}2.63 * * \\
(0.96)\end{array}$ & $\begin{array}{c}1.00 \\
(0.34) \\
\end{array}$ & $\begin{array}{c}1.19 \\
(0.50) \\
\end{array}$ & $\begin{array}{l}3.42 * * \\
(1.06)\end{array}$ & $\begin{array}{c}0.91 \\
(0.33) \\
\end{array}$ & $\begin{array}{l}3.05 * * \\
(1.11)\end{array}$ & $\begin{array}{l}2.09 * \\
(0.61)\end{array}$ & $\begin{array}{c}0.81 \\
(0.30) \\
\end{array}$ & $\begin{array}{c}4.06^{* *} \\
(1.39) \\
\end{array}$ \\
\hline
\end{tabular}

Robust standard errors in parentheses

+ significant at $10 \%$; * significant at $5 \%$; * significant at $1 \%$

Baseline hazard rate varies by 4 Census regions 
Table 5. The Effect of Overall HMO Penetration on Hazard Ratio of Service Exit Using Discrete-Time Proportional Hazard Model

\begin{tabular}{|c|c|c|c|c|c|c|c|c|c|c|}
\hline Hazard ratio (SE) & $\begin{array}{l}\text { Inpatient } \\
\text { substance abuse }\end{array}$ & $\begin{array}{l}\text { Outpatient } \\
\text { substance abuse }\end{array}$ & $\begin{array}{l}\text { HIV/AIDS } \\
\text { services }\end{array}$ & $\begin{array}{l}\text { Emergency } \\
\text { department }\end{array}$ & $\begin{array}{l}\text { Trauma } \\
\text { center }\end{array}$ & $\begin{array}{l}\text { Maternity } \\
\text { care }\end{array}$ & Birthing room & Women's center & $\begin{array}{l}\text { Child wellness } \\
\text { center }\end{array}$ & $\begin{array}{l}\text { Sports } \\
\text { medicine }\end{array}$ \\
\hline \multicolumn{11}{|c|}{ Using Prentice-Gloeckler (1978) Discrete Time Proportional Hazard Model } \\
\hline \multicolumn{11}{|c|}{$1990-1994$} \\
\hline \multirow[t]{2}{*}{ Medium HMO markets } & $0.69+$ & $0.55 * *$ & -- & $0.60+$ & 0.84 & $0.45^{* *}$ & $0.42 * *$ & $0.53 *$ & -- & 0.80 \\
\hline & $(0.16)$ & $(0.11)$ & -- & $(0.18)$ & $(0.25)$ & $(0.12)$ & $(0.12)$ & $(0.14)$ & -- & $(0.16)$ \\
\hline \multirow[t]{2}{*}{ High HMO markets } & 0.94 & 0.75 & -- & 0.70 & 0.78 & 0.63 & $0.62 *$ & 0.77 & -- & $0.60 *$ \\
\hline & $(0.22)$ & $(0.14)$ & -- & $(0.23)$ & $(0.25)$ & $(0.21)$ & $(0.15)$ & $(0.19)$ & -- & $(0.13)$ \\
\hline \multicolumn{11}{|l|}{ 1995-1999 } \\
\hline \multirow[t]{2}{*}{ Medium HMO markets } & 0.80 & 0.86 & $0.65^{*}$ & $0.53+$ & $0.68 *$ & $0.65^{*}$ & $0.49 * *$ & $0.55 * *$ & 0.86 & 0.74 \\
\hline & $(0.15)$ & $(0.14)$ & $(0.13)$ & $(0.18)$ & $(0.13)$ & $(0.13)$ & $(0.13)$ & $(0.11)$ & $(0.23)$ & $(0.13)$ \\
\hline \multirow[t]{2}{*}{ High HMO markets } & 0.96 & 0.95 & 0.89 & 1.05 & 1.09 & 0.88 & $0.66+$ & 0.86 & 1.16 & $0.62 *$ \\
\hline & $(0.20)$ & $(0.17)$ & $(0.19)$ & $(0.28)$ & $(0.26)$ & $(0.19)$ & $(0.16)$ & $(0.15)$ & $(0.25)$ & $(0.12)$ \\
\hline \multicolumn{11}{|l|}{$\underline{2000-2003}$} \\
\hline \multirow{2}{*}{ 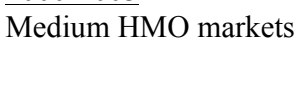 } & 1.25 & $1.38+$ & 1.06 & 1.12 & $1.70 * *$ & 1.09 & 1.44 & $1.65^{*}$ & $1.52 *$ & $1.42+$ \\
\hline & $(0.25)$ & $(0.26)$ & $(0.21)$ & $(0.31)$ & $(0.30)$ & $(0.25)$ & $(0.39)$ & $(0.33)$ & $(0.31)$ & $(0.27)$ \\
\hline \multirow[t]{2}{*}{ High HMO markets } & 0.81 & 1.26 & 1.00 & 1.33 & $2.34 * *$ & 0.97 & $1.78 *$ & $1.60 *$ & $2.36^{* *}$ & 1.28 \\
\hline & $(0.22)$ & $(0.23)$ & $(0.20)$ & $(0.31)$ & $(0.53)$ & $(0.24)$ & $(0.43)$ & $(0.31)$ & $(0.52)$ & $(0.23)$ \\
\hline \multicolumn{11}{|c|}{ Using Cox (1972) Proportional Hazard Model } \\
\hline \multicolumn{11}{|c|}{$1990-1994$} \\
\hline \multirow[t]{2}{*}{ Medium HMO markets } & 0.70 & $0.57 * *$ & -- & 0.66 & 0.86 & $0.50 * *$ & $0.47 * *$ & $0.55^{*}$ & -- & 0.81 \\
\hline & $(0.15)$ & $(0.12)$ & -- & $(0.19)$ & $(0.25)$ & $(0.13)$ & $(0.13)$ & $(0.14)$ & -- & $(0.16)$ \\
\hline \multirow[t]{2}{*}{ High HMO markets } & 0.95 & 0.78 & -- & 0.75 & 0.78 & 0.68 & $0.63+$ & 0.77 & -- & $0.59 *$ \\
\hline & $(0.21)$ & $(0.14)$ & -- & $(0.23)$ & $(0.24)$ & $(0.21)$ & $(0.15)$ & $(0.18)$ & -- & $(0.13)$ \\
\hline \multicolumn{11}{|l|}{$1995-1999$} \\
\hline \multirow[t]{2}{*}{ Medium HMO markets } & 0.81 & 0.85 & $0.67 *$ & $0.54 *$ & $0.70+$ & $0.68^{*}$ & $0.51 * *$ & $0.56^{* *}$ & 0.88 & 0.76 \\
\hline & $(0.14)$ & $(0.13)$ & $(0.13)$ & $(0.17)$ & $(0.14)$ & $(0.13)$ & $(0.13)$ & $(0.11)$ & $(0.22)$ & $(0.13)$ \\
\hline \multirow[t]{2}{*}{ High HMO markets } & 0.94 & 0.90 & 0.90 & 0.99 & 1.07 & 0.88 & $0.66+$ & 0.79 & 1.19 & $0.61 *$ \\
\hline & $(0.19)$ & $(0.16)$ & $(0.18)$ & $(0.24)$ & $(0.23)$ & $(0.18)$ & $(0.15)$ & $(0.14)$ & $(0.24)$ & $(0.12)$ \\
\hline \multicolumn{11}{|l|}{$\underline{2000-2003}$} \\
\hline \multirow[t]{2}{*}{ Medium HMO markets } & 1.29 & $1.39+$ & 1.05 & 1.14 & $1.60 * *$ & 1.10 & 1.36 & $1.60 *$ & $1.45+$ & $1.41+$ \\
\hline & $(0.24)$ & $(0.25)$ & $(0.20)$ & $(0.30)$ & $(0.27)$ & $(0.24)$ & $(0.35)$ & $(0.30)$ & $(0.28)$ & $(0.25)$ \\
\hline \multirow[t]{2}{*}{ High HMO markets } & 0.86 & 1.26 & 1.00 & 1.32 & $2.26^{* *}$ & 1.01 & $1.65^{*}$ & $1.54^{*}$ & $2.20 * *$ & 1.30 \\
\hline & $(0.22)$ & $(0.22)$ & $(0.19)$ & $(0.29)$ & $(0.48)$ & $(0.23)$ & $(0.40)$ & $(0.30)$ & $(0.46)$ & $(0.23)$ \\
\hline Observations & $570^{\prime}$ & 8713 & 8462 & 26497 & 8172 & 20412 & 20732 & 14801 & 4087 & 10537 \\
\hline
\end{tabular}

Robust standard errors in parentheses

+ significant at $10 \% ; *$ significant at $5 \% ; * *$ significant at $1 \%$

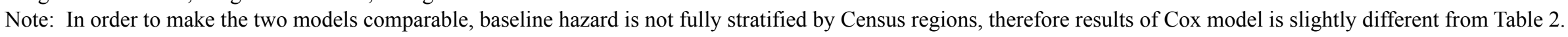


Table 6. The Effect of Overall HMO on Hazard Ratio of Service Exit

(Restrict to hospitals operating continuously between 1991-2003)

\begin{tabular}{|c|c|c|c|c|c|c|c|c|c|c|}
\hline Hazard ratio (SE) & $\begin{array}{l}\text { Inpatient } \\
\text { substance abuse }\end{array}$ & $\begin{array}{l}\text { Outpatient } \\
\text { substance abuse }\end{array}$ & $\begin{array}{l}\text { HIV/AIDS } \\
\text { services }\end{array}$ & $\begin{array}{l}\text { Emergency } \\
\text { department }\end{array}$ & $\begin{array}{l}\text { Trauma } \\
\text { center }\end{array}$ & $\begin{array}{l}\text { Maternity } \\
\text { care }\end{array}$ & Birthing room & $\begin{array}{l}\text { Women's } \\
\text { center }\end{array}$ & $\begin{array}{l}\text { Child wellness } \\
\text { center }\end{array}$ & $\begin{array}{l}\text { Sports } \\
\text { medicine }\end{array}$ \\
\hline \multicolumn{11}{|l|}{ Overall } \\
\hline $\begin{array}{l}\text { Low HMO Markets } \\
\text { (reference group) }\end{array}$ & 1.0 & 1.0 & 1.0 & 1.0 & 1.0 & 1.0 & 1.0 & 1.0 & 1.0 & 1.0 \\
\hline Medium HMO markets & $\begin{array}{c}0.88 \\
(0.13)\end{array}$ & $\begin{array}{c}0.92 \\
(0.12)\end{array}$ & $\begin{array}{c}0.94 \\
(0.14)\end{array}$ & $\begin{array}{c}0.70 \\
(0.20)\end{array}$ & $\begin{array}{c}1.01 \\
(0.17)\end{array}$ & $\begin{array}{c}0.74 \\
(0.16)\end{array}$ & $\begin{array}{c}0.69 \\
(0.17)\end{array}$ & $\begin{array}{c}0.90 \\
(0.19)\end{array}$ & $\begin{array}{c}1.14 \\
(0.23)\end{array}$ & $\begin{array}{c}1.00 \\
(0.16)\end{array}$ \\
\hline High HMO markets & $\begin{array}{c}0.88 \\
(0.16)\end{array}$ & $\begin{array}{c}0.98 \\
(0.16)\end{array}$ & $\begin{array}{r}0.89 \\
(0.15)\end{array}$ & $\begin{array}{c}0.70 \\
(0.18)\end{array}$ & $\begin{array}{l}1.45+ \\
(0.27)\end{array}$ & $\begin{array}{c}0.76 \\
(0.19)\end{array}$ & $\begin{array}{c}0.79 \\
(0.18)\end{array}$ & $\begin{array}{c}0.94 \\
(0.18)\end{array}$ & $\begin{array}{l}1.69 * \\
(0.36)\end{array}$ & $\begin{array}{c}0.80 \\
(0.14)\end{array}$ \\
\hline \multicolumn{11}{|l|}{ By Periods } \\
\hline 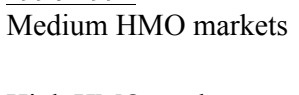 & $\begin{array}{l}0.57 * \\
(0.16)\end{array}$ & $\begin{array}{c}0.47 * * \\
(0.13)\end{array}$ & -- & $\begin{array}{l}0.33 * \\
(0.18)\end{array}$ & $\begin{array}{c}0.70 \\
(0.24)\end{array}$ & $\begin{array}{c}0.24 * * \\
(0.12)\end{array}$ & $\begin{array}{c}0.32 * * \\
(0.13)\end{array}$ & $\begin{array}{l}0.55+ \\
(0.19)\end{array}$ & $\begin{array}{l}-- \\
--\end{array}$ & $\begin{array}{c}0.80 \\
(0.22)\end{array}$ \\
\hline High HMO markets & $\begin{array}{c}0.99 \\
(0.22)\end{array}$ & $\begin{array}{c}0.77 \\
(0.16)\end{array}$ & -- & $\begin{array}{l}0.26^{*} \\
(0.14)\end{array}$ & $\begin{array}{c}0.72 \\
(0.23)\end{array}$ & $\begin{array}{l}0.38+ \\
(0.20)\end{array}$ & $\begin{array}{l}0.47^{*} \\
(0.18)\end{array}$ & $\begin{array}{l}0.56+ \\
(0.19)\end{array}$ & -- & $\begin{array}{l}0.58+ \\
(0.18)\end{array}$ \\
\hline \multicolumn{11}{|l|}{$\underline{1995-1999}$} \\
\hline Medium HMO markets & $\begin{array}{c}0.83 \\
(0.14)\end{array}$ & $\begin{array}{c}0.83 \\
(0.15)\end{array}$ & $\begin{array}{c}0.71 \\
(0.18)\end{array}$ & $\begin{array}{l}0.23 * * \\
(0.12)\end{array}$ & $\begin{array}{l}0.61 * \\
(0.14)\end{array}$ & $\begin{array}{l}0.58^{*} \\
(0.15)\end{array}$ & $\begin{array}{l}0.37 * * \\
(0.13)\end{array}$ & $\begin{array}{l}0.45^{* *} \\
(0.12)\end{array}$ & $\begin{array}{c}0.74 \\
(0.21)\end{array}$ & $\begin{array}{c}0.74 \\
(0.14)\end{array}$ \\
\hline High HMO markets & $\begin{array}{c}0.92 \\
(0.20)\end{array}$ & $\begin{array}{c}0.86 \\
(0.18)\end{array}$ & $\begin{array}{c}0.84 \\
(0.26)\end{array}$ & $\begin{array}{l}0.53+ \\
(0.18)\end{array}$ & $\begin{array}{c}0.79 \\
(0.25)\end{array}$ & $\begin{array}{c}0.81 \\
(0.23)\end{array}$ & $\begin{array}{l}0.41 * * \\
(0.12)\end{array}$ & $\begin{array}{l}0.61 * \\
(0.15)\end{array}$ & $\begin{array}{c}1.13 \\
(0.28)\end{array}$ & $\begin{array}{c}0.57 * * \\
(0.12)\end{array}$ \\
\hline \multicolumn{11}{|l|}{$\underline{2000-2003}$} \\
\hline Medium HMO markets & $\begin{array}{c}1.25 \\
(0.24)\end{array}$ & $\begin{array}{l}1.55^{*} \\
(0.30)\end{array}$ & $\begin{array}{c}1.02 \\
(0.20)\end{array}$ & $\begin{array}{c}1.26 \\
(0.43)\end{array}$ & $\begin{array}{l}1.54 * \\
(0.32)\end{array}$ & $\begin{array}{c}1.19 \\
(0.32)\end{array}$ & $\begin{array}{c}1.48 \\
(0.49)\end{array}$ & $\begin{array}{l}1.78 * \\
(0.42)\end{array}$ & $\begin{array}{l}1.52 * \\
(0.32)\end{array}$ & $\begin{array}{l}1.53 * \\
(0.30)\end{array}$ \\
\hline High HMO markets & $\begin{array}{c}0.76 \\
(0.21) \\
\end{array}$ & $\begin{array}{c}1.36 \\
(0.27) \\
\end{array}$ & $\begin{array}{l}1.23 \\
(0.26) \\
\end{array}$ & $\begin{array}{l}1.06 \\
(0.31) \\
\end{array}$ & $\begin{array}{c}2.51 * * \\
(0.51) \\
\end{array}$ & $\begin{array}{c}0.92 \\
(0.26) \\
\end{array}$ & $\begin{array}{l}1.53 \\
(0.43) \\
\end{array}$ & $\begin{array}{l}1.62 * \\
(0.37) \\
\end{array}$ & $\begin{array}{l}2.09 * * \\
(0.49) \\
\end{array}$ & $\begin{array}{c}1.32 \\
(0.25) \\
\end{array}$ \\
\hline Observations & 4621 & 7307 & 7375 & 22043 & 7229 & 17664 & 17957 & 12642 & 3673 & 9068 \\
\hline
\end{tabular}

Robust standard errors in parentheses

+ significant at $10 \% ; *$ significant at $5 \% ; * *$ significant at $1 \%$

Baseline hazard rate varies by 4 Census regions 
Table 7. The Effect of Overall HMO Penetration on Hazard Ratio of Service Exit

(Including early adopter indicator)

\begin{tabular}{|c|c|c|c|c|c|c|c|c|c|c|}
\hline Hazard ratio (SE) & $\begin{array}{l}\text { Inpatient } \\
\text { substance abuse }\end{array}$ & $\begin{array}{l}\text { Outpatient } \\
\text { substance abuse }\end{array}$ & $\begin{array}{l}\text { HIV/AIDS } \\
\text { services }\end{array}$ & $\begin{array}{l}\text { Emergency } \\
\text { department }\end{array}$ & $\begin{array}{l}\text { Trauma } \\
\text { center }\end{array}$ & $\begin{array}{l}\text { Maternity } \\
\text { care }\end{array}$ & Birthing room & Women's center & $\begin{array}{l}\text { Child wellness } \\
\text { center }\end{array}$ & $\begin{array}{l}\text { Sports } \\
\text { medicine }\end{array}$ \\
\hline \multicolumn{11}{|l|}{ Overall } \\
\hline Medium HMO markets & $\begin{array}{c}0.92 \\
(0.12)\end{array}$ & $\begin{array}{c}0.93 \\
(0.11)\end{array}$ & $\begin{array}{c}0.91 \\
(0.12)\end{array}$ & $\begin{array}{c}0.80 \\
(0.16)\end{array}$ & $\begin{array}{l}1.16 \\
(0.17)\end{array}$ & $\begin{array}{c}0.79 \\
(0.13)\end{array}$ & $\begin{array}{c}0.74 \\
(0.14)\end{array}$ & $\begin{array}{c}0.89 \\
(0.14)\end{array}$ & $\begin{array}{c}1.17 \\
(0.21)\end{array}$ & $\begin{array}{c}0.97 \\
(0.13)\end{array}$ \\
\hline High HMO markets & $\begin{array}{c}0.95 \\
(0.16)\end{array}$ & $\begin{array}{c}0.99 \\
(0.13)\end{array}$ & $\begin{array}{l}1.04 \\
(0.17)\end{array}$ & $\begin{array}{c}1.02 \\
(0.19)\end{array}$ & $\begin{array}{l}1.56^{*} \\
(0.29)\end{array}$ & $\begin{array}{c}0.84 \\
(0.15)\end{array}$ & $\begin{array}{c}0.87 \\
(0.15)\end{array}$ & $\begin{array}{c}1.04 \\
(0.15)\end{array}$ & $\begin{array}{l}1.67 * * \\
(0.31)\end{array}$ & $\begin{array}{c}0.85 \\
(0.14)\end{array}$ \\
\hline Early adopter indicator & $\begin{array}{c}0.64 * * \\
(0.07) \\
\end{array}$ & $\begin{array}{c}0.55 * * \\
(0.06) \\
\end{array}$ & & $\begin{array}{c}0.63 * * \\
(0.10) \\
\end{array}$ & $\begin{array}{c}0.47 * * \\
(0.08) \\
\end{array}$ & $\begin{array}{c}0.60 * * \\
(0.07) \\
\end{array}$ & $\begin{array}{c}0.51 * * \\
(0.07) \\
\end{array}$ & $\begin{array}{c}0.56 * * \\
(0.07) \\
\end{array}$ & $\begin{array}{c}0.48 * * \\
(0.06) \\
\end{array}$ & $\begin{array}{l}0.51 * * \\
(0.05) \\
\end{array}$ \\
\hline \multicolumn{11}{|l|}{ By Periods } \\
\hline Medium HMO markets & $\begin{array}{c}0.81 \\
(0.18)\end{array}$ & $\begin{array}{c}0.75 \\
(0.16)\end{array}$ & -- & $\begin{array}{c}0.83 \\
(0.29)\end{array}$ & $\begin{array}{c}1.10 \\
(0.34)\end{array}$ & $\begin{array}{c}0.67 \\
(0.19)\end{array}$ & $\begin{array}{l}0.62+ \\
(0.17)\end{array}$ & $\begin{array}{c}0.65 \\
(0.19)\end{array}$ & -- & $\begin{array}{c}1.14 \\
(0.24)\end{array}$ \\
\hline High HMO markets & $\begin{array}{c}1.09 \\
(0.25)\end{array}$ & $\begin{array}{c}1.01 \\
(0.19)\end{array}$ & -- & $\begin{array}{c}1.01 \\
(0.39)\end{array}$ & $\begin{array}{c}0.96 \\
(0.31)\end{array}$ & $\begin{array}{c}0.76 \\
(0.25)\end{array}$ & $\begin{array}{c}0.80 \\
(0.21)\end{array}$ & $\begin{array}{c}0.89 \\
(0.23)\end{array}$ & $\begin{array}{l}-- \\
--\end{array}$ & $\begin{array}{c}0.86 \\
(0.21)\end{array}$ \\
\hline \multicolumn{11}{|l|}{ 1995-1999 } \\
\hline Medium HMO markets & $\begin{array}{c}0.85 \\
(0.14)\end{array}$ & $\begin{array}{c}0.85 \\
(0.12)\end{array}$ & $\begin{array}{l}0.71+ \\
(0.14)\end{array}$ & $\begin{array}{l}0.50^{*} \\
(0.15)\end{array}$ & $\begin{array}{c}0.75 \\
(0.14)\end{array}$ & $\begin{array}{l}0.69+ \\
(0.13)\end{array}$ & $\begin{array}{c}0.48 * * \\
(0.12)\end{array}$ & $\begin{array}{c}0.56^{* *} \\
(0.11)\end{array}$ & $\begin{array}{c}1.06 \\
(0.27)\end{array}$ & $\begin{array}{c}0.76 \\
(0.13)\end{array}$ \\
\hline High HMO markets & $\begin{array}{c}1.01 \\
(0.20)\end{array}$ & $\begin{array}{c}0.90 \\
(0.16)\end{array}$ & $\begin{array}{c}0.91 \\
(0.21)\end{array}$ & $\begin{array}{c}1.19 \\
(0.28)\end{array}$ & $\begin{array}{c}1.05 \\
(0.25)\end{array}$ & $\begin{array}{c}0.96 \\
(0.19)\end{array}$ & $\begin{array}{l}0.69+ \\
(0.15)\end{array}$ & $\begin{array}{c}0.85 \\
(0.15)\end{array}$ & $\begin{array}{l}1.45+ \\
(0.32)\end{array}$ & $\begin{array}{l}0.68+ \\
(0.14)\end{array}$ \\
\hline \multicolumn{11}{|l|}{ 2000-2003 } \\
\hline Medium HMO markets & $\begin{array}{c}1.11 \\
(0.19)\end{array}$ & $\begin{array}{c}1.19 \\
(0.21)\end{array}$ & $\begin{array}{c}1.12 \\
(0.22)\end{array}$ & $\begin{array}{c}1.13 \\
(0.28)\end{array}$ & $\begin{array}{l}1.49^{*} \\
(0.25)\end{array}$ & $\begin{array}{c}0.96 \\
(0.20)\end{array}$ & $\begin{array}{c}1.17 \\
(0.28)\end{array}$ & $\begin{array}{l}1.46^{*} \\
(0.28)\end{array}$ & $\begin{array}{c}1.26 \\
(0.25)\end{array}$ & $\begin{array}{c}1.17 \\
(0.20)\end{array}$ \\
\hline High HMO markets & $\begin{array}{c}0.78 \\
(0.19) \\
\end{array}$ & $\begin{array}{c}1.07 \\
(0.18)\end{array}$ & $\begin{array}{l}1.16 \\
(0.23)\end{array}$ & $\begin{array}{c}0.88 \\
(0.20) \\
\end{array}$ & $\begin{array}{c}2.36^{* *} \\
(0.48) \\
\end{array}$ & $\begin{array}{c}0.75 \\
(0.16)\end{array}$ & $\begin{array}{l}1.19 \\
(0.29)\end{array}$ & $\begin{array}{l}1.39+ \\
(0.27)\end{array}$ & $\begin{array}{l}1.82 * * \\
(0.38)\end{array}$ & $\begin{array}{c}1.07 \\
(0.19) \\
\end{array}$ \\
\hline Observations & 5636 & 8665 & 8411 & 26252 & 8149 & 20306 & 20587 & 14689 & 4073 & 104 \\
\hline
\end{tabular}

Robust standard errors in parentheses

+ significant at 10\%; * significant at 5\%; ** significant at $1 \%$

Baseline hazard rate varies by 4 Census regions 
Table 8. The Effect of Overall Managed Care Penetration (HMO + PPO) on Hazard Ratio of Service Exit

\begin{tabular}{|c|c|c|c|c|c|c|c|c|c|c|}
\hline Hazard ratio (SE) & $\begin{array}{l}\text { Inpatient } \\
\text { substance abuse }\end{array}$ & $\begin{array}{l}\text { Outpatient } \\
\text { substance abuse }\end{array}$ & $\begin{array}{l}\text { HIV/AIDS } \\
\text { services }\end{array}$ & $\begin{array}{l}\text { Emergency } \\
\text { department }\end{array}$ & $\begin{array}{l}\text { Trauma } \\
\text { center }\end{array}$ & $\begin{array}{l}\text { Maternity } \\
\text { care }\end{array}$ & Birthing room & Women's center & $\begin{array}{l}\text { Child wellness } \\
\text { center }\end{array}$ & $\begin{array}{l}\text { Sports } \\
\text { medicine }\end{array}$ \\
\hline \multicolumn{11}{|l|}{ Overall } \\
\hline $\begin{array}{l}\text { Low MC Markets } \\
\text { (reference group) }\end{array}$ & 1.0 & 1.0 & 1.0 & 1.0 & 1.0 & 1.0 & 1.0 & 1.0 & 1.0 & 1.0 \\
\hline Medium MC markets & $\begin{array}{l}1.03 \\
(0.14)\end{array}$ & $\begin{array}{c}0.93 \\
(0.11)\end{array}$ & $\begin{array}{c}0.96 \\
(0.11)\end{array}$ & $\begin{array}{c}0.95 \\
(0.16)\end{array}$ & $\begin{array}{l}1.31^{*} \\
(0.18)\end{array}$ & $\begin{array}{c}0.88 \\
(0.11)\end{array}$ & $\begin{array}{c}0.91 \\
(0.14)\end{array}$ & $\begin{array}{c}0.94 \\
(0.11)\end{array}$ & $\begin{array}{c}1.22 \\
(0.18)\end{array}$ & $\begin{array}{l}0.75^{*} \\
(0.09)\end{array}$ \\
\hline High MC markets & $\begin{array}{c}0.84 \\
(0.16) \\
\end{array}$ & $\begin{array}{c}0.83 \\
(0.12) \\
\end{array}$ & $\begin{array}{c}0.84 \\
(0.16) \\
\end{array}$ & $\begin{array}{c}0.71 \\
(0.16) \\
\end{array}$ & $\begin{array}{c}1.00 \\
(0.23) \\
\end{array}$ & $\begin{array}{l}0.68^{*} \\
(0.11) \\
\end{array}$ & $\begin{array}{l}0.68+ \\
(0.14) \\
\end{array}$ & $\begin{array}{c}0.87 \\
(0.14) \\
\end{array}$ & $\begin{array}{l}1.02 \\
(0.19) \\
\end{array}$ & $\begin{array}{l}0.71^{*} \\
(0.10) \\
\end{array}$ \\
\hline \multicolumn{11}{|l|}{ By Periods } \\
\hline \multicolumn{11}{|l|}{$\overrightarrow{1990-1994}$} \\
\hline Medium MC markets & $\begin{array}{c}0.82 \\
(0.14)\end{array}$ & $\begin{array}{l}0.61 * * \\
(0.11)\end{array}$ & $\begin{array}{l}-- \\
--\end{array}$ & $\begin{array}{c}0.74 \\
(0.23)\end{array}$ & $\begin{array}{c}0.95 \\
(0.24)\end{array}$ & $\begin{array}{l}0.58^{*} \\
(0.14)\end{array}$ & $\begin{array}{l}0.57^{*} \\
(0.13)\end{array}$ & $\begin{array}{c}0.77 \\
(0.17)\end{array}$ & $\begin{array}{l}-- \\
--\end{array}$ & $\begin{array}{l}0.72+ \\
(0.13)\end{array}$ \\
\hline High MC markets & $\begin{array}{c}0.65 \\
(0.17)\end{array}$ & $\begin{array}{l}0.70+ \\
(0.13)\end{array}$ & $\begin{array}{l}-- \\
--\end{array}$ & $\begin{array}{c}0.78 \\
(0.29)\end{array}$ & $\begin{array}{c}0.73 \\
(0.20)\end{array}$ & $\begin{array}{l}0.47^{*} \\
(0.14)\end{array}$ & $\begin{array}{c}0.48 * * \\
(0.13)\end{array}$ & $\begin{array}{c}0.69 \\
(0.16)\end{array}$ & $\begin{array}{l}-- \\
--\end{array}$ & $\begin{array}{c}0.48 * * \\
(0.12)\end{array}$ \\
\hline \multicolumn{11}{|l|}{ 1995-1999 } \\
\hline$\overline{\text { Medium MC markets }}$ & $\begin{array}{l}1.01 \\
(0.18)\end{array}$ & $\begin{array}{c}0.95 \\
(0.14)\end{array}$ & $\begin{array}{c}0.91 \\
(0.16)\end{array}$ & $\begin{array}{c}0.87 \\
(0.24)\end{array}$ & $\begin{array}{c}0.79 \\
(0.15)\end{array}$ & $\begin{array}{c}0.85 \\
(0.14)\end{array}$ & $\begin{array}{c}0.76 \\
(0.16)\end{array}$ & $\begin{array}{c}0.64 * * \\
(0.10)\end{array}$ & $\begin{array}{c}0.96 \\
(0.17)\end{array}$ & $\begin{array}{c}0.61 * * \\
(0.09)\end{array}$ \\
\hline High MC markets & $\begin{array}{c}0.96 \\
(0.21)\end{array}$ & $\begin{array}{c}0.75 \\
(0.13)\end{array}$ & $\begin{array}{c}0.65 \\
(0.18)\end{array}$ & $\begin{array}{l}0.58+ \\
(0.17)\end{array}$ & $\begin{array}{l}0.56^{*} \\
(0.16)\end{array}$ & $\begin{array}{l}0.68+ \\
(0.14)\end{array}$ & $\begin{array}{c}0.44 * * \\
(0.13)\end{array}$ & $\begin{array}{l}0.64 * \\
(0.14)\end{array}$ & $\begin{array}{c}0.75 \\
(0.19)\end{array}$ & $\begin{array}{c}0.58 * * \\
(0.11)\end{array}$ \\
\hline \multicolumn{11}{|l|}{ 2000-2003 } \\
\hline$\overline{\text { Medium MC markets }}$ & $\begin{array}{l}1.30 \\
(0.22)\end{array}$ & $\begin{array}{l}1.30+ \\
(0.20)\end{array}$ & $\begin{array}{c}1.00 \\
(0.17)\end{array}$ & $\begin{array}{c}1.19 \\
(0.28)\end{array}$ & $\begin{array}{c}1.95 * * \\
(0.32)\end{array}$ & $\begin{array}{c}1.09 \\
(0.21)\end{array}$ & $\begin{array}{l}1.42+ \\
(0.29)\end{array}$ & $\begin{array}{l}1.51 * \\
(0.26)\end{array}$ & $\begin{array}{l}1.46^{*} \\
(0.25)\end{array}$ & $\begin{array}{c}1.00 \\
(0.14)\end{array}$ \\
\hline High MC markets & $\begin{array}{c}0.90 \\
(0.20)\end{array}$ & $\begin{array}{c}1.10 \\
(0.19)\end{array}$ & $\begin{array}{c}1.04 \\
(0.23)\end{array}$ & $\begin{array}{c}0.86 \\
(0.23)\end{array}$ & $\begin{array}{l}1.76^{*} \\
(0.39)\end{array}$ & $\begin{array}{c}0.84 \\
(0.21)\end{array}$ & $\begin{array}{c}1.22 \\
(0.30)\end{array}$ & $\begin{array}{l}1.36+ \\
(0.24)\end{array}$ & $\begin{array}{c}1.31 \\
(0.29)\end{array}$ & $\begin{array}{c}1.06 \\
(0.17)\end{array}$ \\
\hline Observations & 5598 & 8625 & 8353 & 26120 & 8123 & 20234 & 20507 & 14631 & 4053 & 10415 \\
\hline
\end{tabular}

Robust standard errors in parentheses

+ significant at $10 \% ; *$ significant at $5 \% ; * *$ significant at $1 \%$

The break points for low, medium and high managed care markets are $0-40 \%, 40-60 \%,>60 \%$.

Baseline hazard rate varies by 4 Census regions 
Appendix. Complete Results of Main Model

\begin{tabular}{|c|c|c|c|c|c|}
\hline & $\begin{array}{l}\text { Inpatient } \\
\text { substance abuse }\end{array}$ & $\begin{array}{l}\text { Outpatient } \\
\text { substance abuse }\end{array}$ & $\begin{array}{l}\text { HIV/AIDS } \\
\text { services }\end{array}$ & $\begin{array}{l}\text { Emergency } \\
\text { department }\end{array}$ & $\begin{array}{l}\text { Trauma } \\
\text { center }\end{array}$ \\
\hline \multirow[t]{2}{*}{ Medium HMO markets } & 0.89 & 0.89 & 0.86 & 0.80 & 1.11 \\
\hline & $(0.12)$ & $(0.10)$ & $(0.12)$ & $(0.15)$ & $\begin{array}{l}(0.16) \\
148 *\end{array}$ \\
\hline High HMO markets & $\begin{array}{c}0.89 \\
(0.14)\end{array}$ & $\begin{array}{c}0.96 \\
(0.12)\end{array}$ & $\begin{array}{c}0.94 \\
(0.14)\end{array}$ & $\begin{array}{c}1.06 \\
(0.19)\end{array}$ & $\begin{array}{l}1.48^{*} \\
(0.26)\end{array}$ \\
\hline \multirow[t]{2}{*}{ For-profit ownership } & $1.27+$ & $1.29+$ & $1.47 * *$ & 1.05 & 1.31 \\
\hline & $(0.17)$ & $(0.17)$ & $(0.20)$ & $(0.15)$ & $(0.22)$ \\
\hline \multirow[t]{2}{*}{ Government ownership } & 1.17 & 0.99 & 0.89 & $0.62 *$ & 0.74 \\
\hline & $(0.17)$ & $(0.16)$ & $(0.12)$ & $(0.14)$ & $(0.15)$ \\
\hline \multirow[t]{2}{*}{ Ownership converted } & $1.24+$ & $1.35 * *$ & 1.08 & 1.25 & 1.16 \\
\hline & $(0.13)$ & $(0.14)$ & $(0.13)$ & $(0.19)$ & $(0.16)$ \\
\hline \multirow[t]{2}{*}{ Teaching hospital } & $1.27+$ & 0.79 & $0.48 * *$ & 1.20 & $0.43 * *$ \\
\hline & $(0.17)$ & $(0.13)$ & $(0.12)$ & $(0.31)$ & $(0.10)$ \\
\hline \multirow[t]{2}{*}{ System membership } & 1.10 & 1.02 & 0.84 & 1.31 & $1.35+$ \\
\hline & $(0.14)$ & $(0.11)$ & $(0.10)$ & $(0.35)$ & $(0.23)$ \\
\hline \multirow[t]{2}{*}{ Herfindhal index $(\log )$} & 1.16 & $0.68^{*}$ & 0.93 & 0.79 & 0.80 \\
\hline & $(0.21)$ & $(0.11)$ & $(0.22)$ & $(0.19)$ & $(0.18)$ \\
\hline \multirow[t]{2}{*}{ Case mix index $(\log )$} & $2.30^{*}$ & 1.90 & 0.56 & 1.22 & 0.67 \\
\hline & $(0.90)$ & $(0.88)$ & $(0.27)$ & $(0.65)$ & $(0.40)$ \\
\hline \multirow{2}{*}{$\begin{array}{l}\text { Total inpatient discharges } \\
\qquad(\log )\end{array}$} & $0.81 * *$ & $0.86+$ & $0.78^{* *}$ & $0.73^{* *}$ & $0.61 * *$ \\
\hline & $(0.06)$ & $(0.07)$ & $(0.06)$ & $(0.07)$ & $(0.07)$ \\
\hline \multirow{2}{*}{$\begin{array}{l}\text { Total outpatient visits } \\
(\log )\end{array}$} & 0.94 & $0.85^{* *}$ & $0.89+$ & $0.82+$ & 0.96 \\
\hline & $(0.06)$ & $(0.04)$ & $(0.06)$ & $(0.08)$ & $(0.11)$ \\
\hline \multirow[t]{2}{*}{ Area wage index } & $0.45+$ & $0.42 *$ & 0.56 & 0.68 & $0.24 *$ \\
\hline & $(0.21)$ & $(0.18)$ & $(0.27)$ & $(0.41)$ & $(0.15)$ \\
\hline \multirow[t]{2}{*}{ MSA population (log) } & 1.04 & 1.00 & 1.05 & 1.08 & 1.06 \\
\hline & $(0.07)$ & $(0.05)$ & $(0.06)$ & $(0.07)$ & $(0.07)$ \\
\hline \multirow[t]{2}{*}{ Per capita income (log) } & $1.57^{*}$ & $1.46+$ & 1.33 & 1.17 & $1.93^{*}$ \\
\hline & $(0.34)$ & $(0.29)$ & $(0.30)$ & $(0.34)$ & $(0.53)$ \\
\hline$\%$ FP hospitals within & 1.15 & 1.56 & 1.02 & 1.44 & 0.52 \\
\hline 15-mile radius & $(0.46)$ & $(0.48)$ & $(0.40)$ & $(0.81)$ & $(0.24)$ \\
\hline$\%$ GOV hospitals within & 1.46 & 1.68 & 1.17 & $2.63 * *$ & $2.50+$ \\
\hline 15-mile radius & $(0.72)$ & $(0.75)$ & $(0.57)$ & $(0.95)$ & $(1.19)$ \\
\hline Observations & 5707 & 8713 & 8462 & 26497 & 8172 \\
\hline
\end{tabular}

Robust standard errors in parentheses

+ significant at $10 \%$; significant at $5 \%$;** significant at $1 \%$ 


\begin{tabular}{|c|c|c|c|c|c|}
\hline & $\begin{array}{l}\text { Maternity } \\
\text { care }\end{array}$ & $\begin{array}{l}\text { Birthing } \\
\text { room }\end{array}$ & $\begin{array}{l}\text { Women's } \\
\text { health center }\end{array}$ & $\begin{array}{l}\text { Child wellness } \\
\text { center }\end{array}$ & $\begin{array}{l}\text { Sports } \\
\text { medicine }\end{array}$ \\
\hline \multirow[t]{2}{*}{ Medium HMO markets } & 0.78 & $0.73+$ & 0.85 & 1.16 & 0.95 \\
\hline & $(0.13)$ & $(0.14)$ & $(0.14)$ & $(0.21)$ & $(0.13)$ \\
\hline \multirow[t]{2}{*}{ High HMO markets } & 0.88 & 0.93 & 1.01 & $1.74 * *$ & 0.81 \\
\hline & $(0.16)$ & $(0.17)$ & $(0.15)$ & $(0.32)$ & $(0.13)$ \\
\hline \multirow[t]{2}{*}{ For-profit ownership } & 1.01 & 0.97 & 1.05 & $1.83 * *$ & 1.04 \\
\hline & $(0.13)$ & $(0.11)$ & $(0.14)$ & $(0.29)$ & $(0.14)$ \\
\hline \multirow[t]{2}{*}{ Government ownership } & 1.11 & 1.00 & 1.21 & 0.96 & 0.82 \\
\hline & $(0.16)$ & $(0.16)$ & $(0.18)$ & $(0.16)$ & $(0.12)$ \\
\hline \multirow[t]{2}{*}{ Ownership converted } & 0.97 & $1.28 *$ & 1.08 & 0.97 & 0.95 \\
\hline & $(0.13)$ & $(0.15)$ & $(0.12)$ & $(0.16)$ & $(0.12)$ \\
\hline \multirow[t]{2}{*}{ Teaching hospital } & 0.96 & 1.02 & $0.65+$ & $0.68 *$ & 0.88 \\
\hline & $(0.23)$ & $(0.19)$ & $(0.16)$ & $(0.13)$ & $(0.14)$ \\
\hline \multirow[t]{2}{*}{ System membership } & $1.71 * *$ & $1.44 *$ & 1.15 & 1.30 & 1.10 \\
\hline & $(0.27)$ & $(0.23)$ & $(0.15)$ & $(0.24)$ & $(0.13)$ \\
\hline \multirow[t]{2}{*}{ Herfindhal index (log) } & $0.52 * *$ & $0.54 *$ & 0.81 & 0.81 & $0.62 *$ \\
\hline & $(0.11)$ & $(0.13)$ & $(0.17)$ & $(0.15)$ & $(0.13)$ \\
\hline \multirow[t]{2}{*}{ Case mix index $(\log )$} & 1.96 & 1.55 & 0.78 & 0.95 & 0.56 \\
\hline & $(0.97)$ & $(0.88)$ & $(0.39)$ & $(0.55)$ & $(0.22)$ \\
\hline \multirow{2}{*}{$\begin{array}{l}\text { Total inpatient discharg } \\
\quad(\log )\end{array}$} & $0.52 * *$ & $0.50 * *$ & $0.60 * *$ & $0.78 * *$ & 0.87 \\
\hline & $(0.06)$ & $(0.05)$ & $(0.05)$ & $(0.07)$ & $(0.08)$ \\
\hline \multirow{2}{*}{$\begin{array}{l}\text { Total outpatient visits } \\
\quad(\log )\end{array}$} & $0.83 *$ & 0.87 & $0.78 * *$ & $0.85 *$ & $0.78 * *$ \\
\hline & $(0.07)$ & $(0.08)$ & $(0.05)$ & $(0.06)$ & $(0.06)$ \\
\hline \multirow[t]{2}{*}{ Area wage index } & $0.30 *$ & $0.28 *$ & 1.75 & 2.33 & $0.36+$ \\
\hline & $(0.18)$ & $(0.16)$ & $(0.76)$ & $(1.66)$ & $(0.21)$ \\
\hline \multirow[t]{2}{*}{ MSA population (log) } & 1.08 & $1.15^{*}$ & $1.10+$ & $0.90+$ & $1.11 *$ \\
\hline & $(0.07)$ & $(0.08)$ & $(0.06)$ & $(0.05)$ & $(0.06)$ \\
\hline \multirow[t]{2}{*}{ Per capita income (log) } & $2.44 * *$ & $2.10 * *$ & $1.52 *$ & $1.46+$ & $1.63 *$ \\
\hline & $(0.54)$ & $(0.51)$ & $(0.27)$ & $(0.30)$ & $(0.38)$ \\
\hline$\%$ FP hospitals within & 1.13 & 0.66 & 1.29 & 0.97 & 0.63 \\
\hline 15-mile radius & $(0.43)$ & $(0.30)$ & $(0.48)$ & $(0.44)$ & $(0.20)$ \\
\hline$\%$ GOV hospitals withi & 1.78 & $2.37 *$ & 1.19 & 1.58 & 1.69 \\
\hline 15-mile radius & $(0.83)$ & $(0.86)$ & $(0.46)$ & $(0.81)$ & $(0.73)$ \\
\hline Observations & 20412 & 20732 & 14801 & 4087 & 10537 \\
\hline
\end{tabular}

